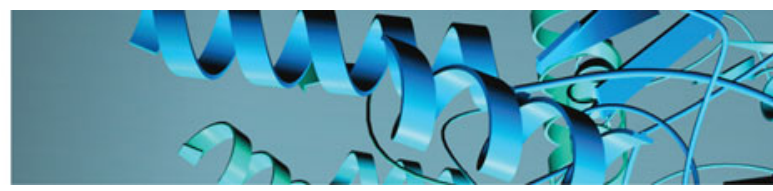

REVIEW

\title{
Molecular mechanisms of xeroderma pigmentosum (XP) proteins
}

\author{
Sandra C. Koch, Nina Simon, Charlotte Ebert and Thomas Carell*
}

Center for Integrated Protein Science at the Department of Chemistry, Ludwig-Maximilians Universität München, Butenandtstr. 5-13, 81377 Munich, Germany

Quarterly Reviews of Biophysics (2016), 49, e5, pages 1 of 32 doi:10.1017/S0033583515000268

Abstract. Nucleotide excision repair (NER) is a highly versatile and efficient DNA repair process, which is responsible for the removal of a large number of structurally diverse DNA lesions. Its extreme broad substrate specificity ranges from DNA damages formed upon exposure to ultraviolet radiation to numerous bulky DNA adducts induced by mutagenic environmental chemicals and cytotoxic drugs used in chemotherapy. Defective NER leads to serious diseases, such as xeroderma pigmentosum (XP). Eight XP complementation groups are known of which seven (XPA-XPG) are caused by mutations in genes involved in the NER process. The eighth gene, XPV, codes for the DNA polymerase $\eta$, which replicates through DNA lesions in a process called translesion synthesis (TLS). Over the past decade, detailed structural information of these DNA repair proteins involved in eukaryotic NER and TLS have emerged. These structures allow us now to understand the molecular mechanism of the NER and TLS processes in quite some detail and we have begun to understand the broad substrate specificity of NER. In this review, we aim to highlight recent advances in the process of damage recognition and repair as well as damage tolerance by the XP proteins.

Key words: NER, xeroderma pigmentosum, crystal structures, DNA repair.

\section{Introduction 2}

1.1. DNA damages 2

1.2. NER and NER-related diseases 2

1.3. NER mechanism 3

1.4. DNA-structure/repair relationships 4

1.5. Damage recognition in NER 4

1.6. Overview of each XP protein and its role in GG-NER 5

\section{XPE (UV-DDB2) 6}

2.1. Crystal structure of human XPE with 6-4PP damaged dsDNA 7

2.2. Crystal structure of human XPE with CPD damaged dsDNA 7

2.3. Crystal structure of human XPE with an abasic lesion site in dsDNA 7

3. XPC 7

3.1. Crystal structure of yeast XPC (Rad4) in complex with a CPD lesion 9

\section{XPB 11}

4.1. Crystal structure of Archaeglobus fulgidus XPB (AfXPB) 11

4.2. Crystal structure of human XPB 12

\section{XPD 12}

5.1. Crystal structure of Sulfolobus acidocaldarius XPD (SaXPD)

* Authors for correspondence: Thomas Carell, Center for Integrated Protein Science at the Department of Chemistry, Ludwig-Maximilians Universität München, Butenandtstr, 5-13, 81377 Munich, Germany. Tel.: +49 (0)89 218077755 Email: thomas.carell@cup.uni-muenchen.de 
5.2. Crystal structure of T. acidophilum (TaXPD) in complex with ssDNA 13

5.3. Proposed model of damage verification 14

6. XPA 15

6.1. Nuclear magnetic resonance (NMR) structure of the DBD of human XPA 15

6.2. Crystal structures of Rad14 with AAF-dG and cisplatin containing dsDNA 17

\section{XPF-ERCC1 17}

7.1. Crystal structure of human XPF-ERCC1 18

7.2. NMR structure of C-terminal human XPF in complex with ssDNA 18

8. XPG 19

8.1. Crystal structure of the yeast XPG (Rad2) in complex with dsDNA

9. XPV 21

9.1. Crystal structure of the yeast XPV $(\operatorname{Rad} 30)$ protein 21

9.2. Crystal structure of the yeast XPV $(\operatorname{Rad} 30)$ in complex with 1,2-GG cisplatin 21

9.3. Crystal structure of the yeast XPV $(\operatorname{Rad} 30)$ in complex with the CPD lesion 21

9.4. Crystal structure of the human XPV in complex with the CPD lesion 22

10. Conclusion 23

Acknowledgements 24

References 24

\section{Introduction}

\subsection{DNA damages}

The DNA is attacked daily by ultraviolet (UV) radiation, chemical carcinogens, cellular metabolites as well as anti-cancer drugs such as cisplatin (Hoeijmakers, 2001) leading to more than 50000 damages per cell per day (Rajski et al. 2000). To preserve the integrity of the genetic information, all organisms are equipped with a number of DNA repair or tolerance mechanisms such as DNA recombination, base excision repair (BER), mismatch repair (MMR), nucleotide excision repair (NER) and translesion synthesis (TLS) that allow cells to cope with the different lesions (Friedberg, 2005; Ohmori et al. 2001; Rupp \& Howard-Flanders, 1968). In this review, we will focus on eukaryotic NER and TLS.

\subsection{NER and NER-related diseases}

One of the most prominent processes among the DNA repair pathways is the NER. NER is a central pathway safeguarding the genome and cells against induced carcinogenesis, because of its capacity to eliminate a broad range of structurally very different DNA lesions (de Laat et al. 1999; Geacintov et al. 2002; Gillet \& Scharer, 2006; Gunz et al. 1996; Huang et al. 1994) including UV lesions such as cyclobutane-pyrimidine dimers (CPDs) and 6-4 pyrimidine-pyrimidone photoproducts (6-4PPs), numerous bulky chemical adducts, intrastrand crosslinks caused by chemotherapeutics such as cisplatin and oxidative damages (Fig. 1) (Brooks et al. 2000; Demple \& Harrison, 1994). All these lesions do not share the same chemical structures, but they are bulky and they thermodynamically destabilize the DNA helix, except for CPDs.

In humans, mutations of NER components lead to three severe diseases: xeroderma pigmentosum (XP), Cockayne syndrome (CS) and trichothiodystrophy (TTD) (Cleaver, 2000; Lehmann, 2001). The NER pathway is divided in two subpathways: the global genome NER (GG-NER) and the transcription-coupled NER (TC-NER) (Gillet \& Scharer, 2006; Hanawalt \& Spivak, 2008) differing only in their damage recognition step. But NER in chromatin is a complex process and probably uses the proposed 'access-repair-restore' mechanism, which comprises many components (Scharer, 2013). A defect in TC-NER along with a mild transcription effect can cause CS and TTD (Cleaver et al. 2009).

The CS is characterized by developmental impairment, premature aging and sunlight sensitivity. TTD leads to developmental impairment and mental retardation without showing skin cancer predisposition (Cleaver et al. 2009; Lehmann, 2003). Mutations inactivating the GG-NER cause the genetic disorder XP (Cleaver et al. 2009). Persons affected by XP ('children of the moon') need to avoid exposure to sunlight, because they show a high predisposition to UV-induced skin cancer (Berneburg \& Lehmann, 2001; Hebra \& Kaposi, 1874; Lehmann, 2003). Seven complementation groups (XPA-XPG) 


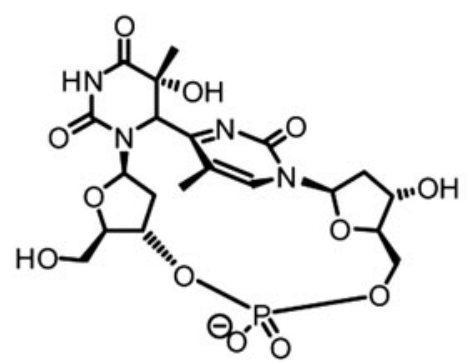

6-4PP

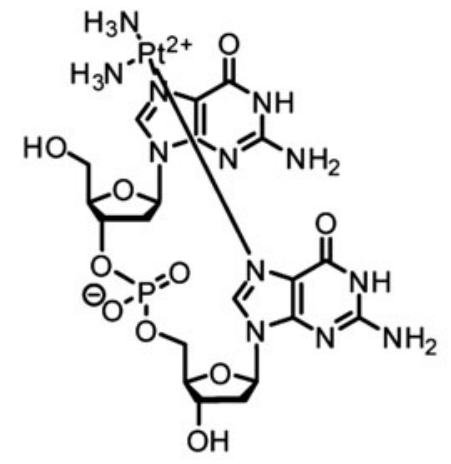

1,2-GG cisplatin

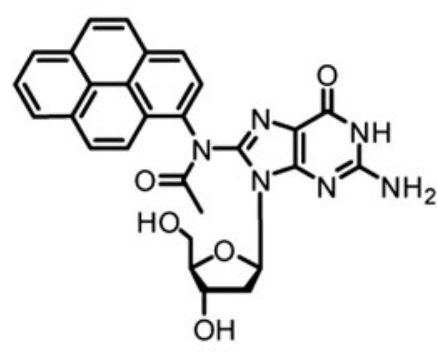

AAP-dG

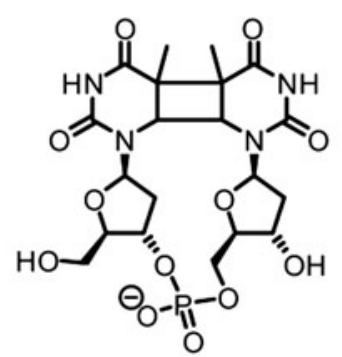

CPD

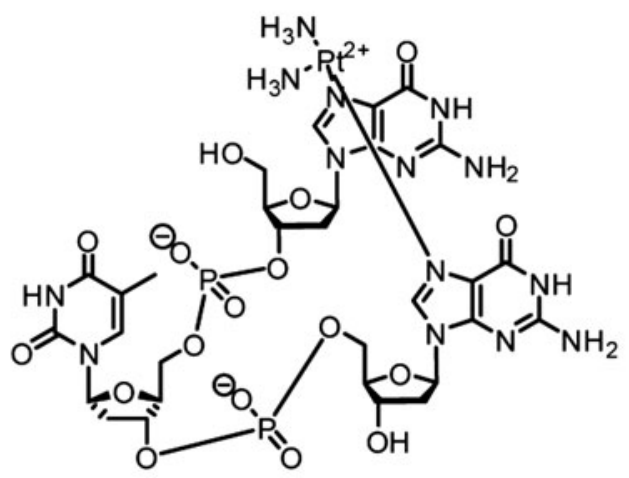

1,3-GTG cisplatin

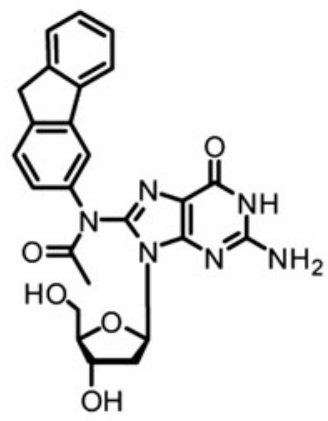

AAF-dG<smiles>Nc1nc2c(nc(Nc3ccc4c(c3)-c3ccccc3C4)n2C2CC(O)C(O)O2)c(=O)[nH]1</smiles>

AF-dG

Fig. 1. Examples of DNA adducts repaired by NER. AAF-dG: $N$-(2'-desoxyguanosin-8-yl)-2-acetylaminofluorene, AF-dG: $N$-(2'-desoxyguanosin-8-yl)-2-aminofluorene AAP-dG: $N$-(2'-desoxyguanosin-8-yl)-2-acetylaminopyrene 6-4PP: 6-4PP, CPD: cyclobutane-pyrimidine dimer, 1,2-GG and 1,3-GTG: major cisplatin-induced intrastrand crosslinks lesions.

associated with different NER gene defects were discovered by cell fusion techniques (De Weerd-Kastelein et al. 1972). The discovery of NER and its association with genetic disorders together with the mechanism of action have already been reviewed (Friedberg, 1995). Mutations associated with XP and posttranslational modifications of the XP proteins have also been recently reported (Feltes \& Bonatto, 2015). The variant form of the human syndrome xeroderma pigmentosum (XPV) (Masutani et al. 1999b) is caused by a defect in DNA polymerase $\eta$. In this paper, we review the eukaryotic structures of XP proteins (XPA-XPG), including the XP variant DNA polymerase $\eta$ (called XPV) in complex with damaged or undamaged DNA. This review will provide insights at the atomic level of how lesions in DNA are processed by these proteins.

\subsection{NER mechanism}

With the exception of chromatin, the NER mechanism is well understood in Escherichia coli as well as in eukaryotes (Naegeli \& Sugasawa, 2011; Sancar \& Tang, 1993; Scharer, 2013). While the repair process in eukaryotes is accomplished by up to 30 
proteins, the precise role of each protein has not been fully elucidated so far. Despite this, a general core repair mechanism has emerged (Fig. 2). In eukaryotes, the NER is divided in two distinct subpathways differing only in their damage recognition step (de Laat et al. 1999; Hanawalt \& Spivak, 2008; Mellon et al. 1987). TC-NER ensures the repair of lesions which are located on the transcribed strand of active genes (Hanawalt \& Spivak, 2008; Hoeijmakers, 2001; Mellon et al. 1987; Sweder \& Hanawalt, 1992). Here the RNA-polymerase II seems to act as the initial damage sensor. During transcription the polymerase gets stalled at the lesion site (Donahue et al. 1994; Tornaletti \& Hanawalt, 1999) and by addition of the protein Cockayne syndrome group B (CSB) a stable CSB-RNAP-DNA complex can from by ATP-hydrolysis (Citterio et al. 2000; Tantin et al. 1997). In case the lesion blocks any read through, downstream factors such as Cockayne syndrome group A protein (CSA) (Kamiuchi et al. 2002), TFIIH (Tantin, 1998) and XPG (Iyer et al. 1996) are recruited to the damage site and repair is initiated (Hanawalt \& Spivak, 2008). The GG-NER in contrast detects and removes helix distorting lesions throughout the whole genome. The exact mechanism of the damage recognition steps is still under debate. Aboussekhra et al. and Mu et al. were able to reconstitute the repair mechanism in vitro allowing deciphering the core excision reaction of NER (Aboussekhra et al. 1995; Mu et al. 1995). The NER assembly seems to be a sequential and coordinated process in which damage excision and repair is mostly error-free. This repair process is characterized by five main steps (steps I-V): after damage recognition (I) a multi-protein complex ('preincision complex' (PIC)) binds to the damage site (II) leading to a double asymmetric cut of the damage-containing oligonucleotide strand. The damage-containing single-stranded DNA (ssDNA) fragment is eliminated (III). Afterwards the double strand is reconstituted by filling the gap with the DNA polymerase (IV) and ligation of the new synthesized strand takes place (V) (Shivji et al. 1995). In this work, we will only consider the GG-NER pathway.

\subsection{DNA-structure/repair relationships}

Because of its broad substrate specificity, it was speculated early on that the NER system does not recognize the lesion itself but the distortion of the DNA structure. In 1997 Naegeli and co-workers discovered that for damage recognition a chemical modification of the nucleotide in addition to distortion in the DNA helix had to be present (Hess et al. 1996b). They could show that neither a modified ribose moiety with intact Watson-Crick base pairing nor a DNA bubble of three base-pairs was recognized and repaired by the NER system. However, placing the modified ribose moiety into a DNA bubble, created a well-recognized NER substrate. These observations helped to formulate the 'bipartite substrate discrimination'-model (Hess et al. 1996a, 1997a). This model shows that only DNA damages that cause disrupted base pairing can be recognized as NER substrates. Furthermore, a DNA helix distortion might be additionally needed for the correct recruitment of the NER machinery (Hess et al. 1996b). This hypothesis explains why helix-distorting damages are more efficiently processed by NER (Gunz et al. 1996; Sugasawa et al. 2001). These ideas can also explain why 6-4PPs are better substrates than CPD lesions. Not all adducts, induced by polyaromatic hydrocarbons or aromatic amines, are good substrates for NER, because some adducts do not change the duplex structure, e.g. $\mathrm{N}$-(deoxyguanosin-8-yl)-2-aminofluorene. The aromatic ring of the lesion is easily accommodated in the minor or major grooves of the DNA duplex. Lesions causing helix disruption upon intercalation of their aromatic ring inside the DNA helix are typically good substrates for NER, e.g. N-(deoxyguanosin-8-yl)-2-acetylaminofluorene (dG-AAF), (Gillet et al. 2005; Mu et al. 1994) or benzo[a]pyrene (Buterin et al. 2000; Geacintov et al. 2002; Hess et al. 1997a; Yan et al. 2003). Nowadays, it is assumed that all parameters able to reduce the thermodynamic stability of the DNA play a role for the NER damage recognition step. The repair rate is apparently proportional to the decrease of thermodynamic stability of the duplex induced by the discrete DNA lesions (Aboussekhra et al. 1995; Geacintov et al. 2002; Gillet \& Scharer, 2006; Gunz et al. 1996).

\subsection{Damage recognition in NER}

How does discrimination between undamaged and damaged DNA take place in the context of dominating undamaged DNA present in the nucleus? The exact damage recognition process in NER is still unclear and as such it is the most challenging current question associated with the NER process.

Several experiments with fluorescein-labeled proteins, such as ERCC1 (Houtsmuller et al. 1999), XPB (Hoogstraten et al. 2002) and XPA (Rademakers et al. 2003), in combination with photobleaching techniques showed that the repair proteins move freely in the nucleus and accumulate successively at the damaged site. These observations argue that recognition factors must initially bind to the damage site and subsequently recruit downstream factors. At the beginning of NER research XPA was thought to be the initial damage recognizer in NER (Asahina et al. 1994; Jones \& Wood, 1993). However, in 1998 Sugasawa et al. (Sugasawa et al. 1998) demonstrated in an in vitro experiment, that the complex XPC-RAD23B was the first damage binder followed by participation of XPA. While for XPC-RAD23B the involvement in the GG-NER pathway has been clearly shown, the complex is not necessary for TC-NER. XPA in contrast, is indispensable for both GG-NER and TC-NER, which perhaps supports its central function in a later step of NER (Kobayashi et al. 1998; Sugasawa et al. 1998). The role of XPA requires further investigations. 
(a)

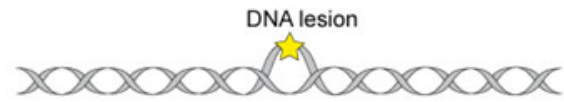

(b)

(c)

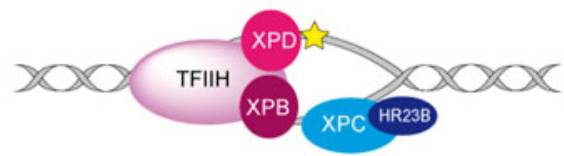

(d)

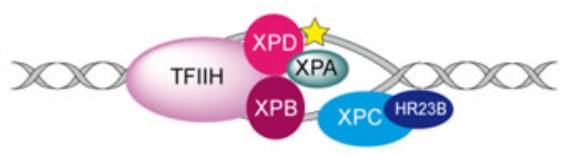

(e)

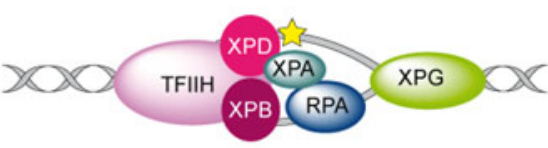

(f)

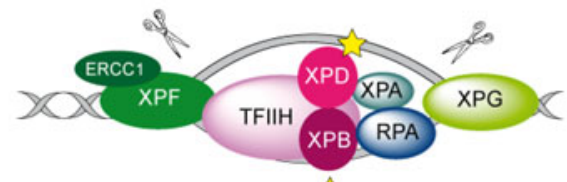

(g)

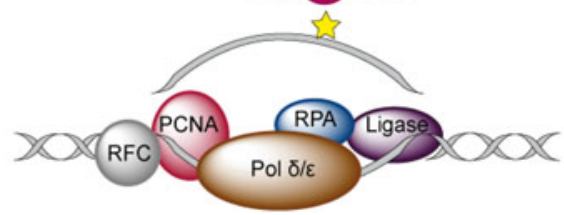

Fig. 2. Overview of the global genome-NER mechanism (Friedberg, 2001; Li et al. 2015).

Biochemical experiments demonstrated that the UV-damaged DNA-binding protein (UV-DDB) (Fujiwara et al. 1999; Keeney et al. 1993; Reardon et al. 1993), XPC-RAD23B (Batty et al. 2000a; Raoul et al. 1995; Sugasawa et al. 1998, 2001), XPA (Buschta-Hedayat et al. 1999; Jones \& Wood, 1993; Li et al. 1995a) and replication protein A (RPA) (Burns et al. 1996; Mellon et al. 1987; Reardon \& Sancar, 2002; Schweizer et al. 1999) show all affinity to damage-containing DNA. XPCRAD23B binds specifically to DNA lesions such as 6-4PP (Batty et al. 2000a; Kusumoto et al. 2001; Raoul et al. 1995), cisplatin (Evans et al. 1997b; Hey et al. 2002; Moggs et al. 1996, 1997; Sugasawa et al. 1998), dG-AAF (Sugasawa et al. 1998) and cholesterol adducts (Kusumoto et al. 2001; Sugasawa et al. 2001). It recognizes CPD damages (Kusumoto et al. 2001) poorly although their repair is strongly dependent on the presence of XPC (Venema et al. 1991). The affinity of XPC-RAD23B to CPDs can be enhanced by mismatches surrounding the lesion (Sugasawa et al. 2001). XPA alone or in combination with RPA binds to DNA containing bulky adducts such as dG-AAF (Liu et al. 2005; Yang et al. 2002). By far the strongest DNA binding for XPA are DNA junctions which suggest that XPA interacts with an intermediate structure rather than directly with a lesion (Missura et al. 2001). Photoaffinity-crosslinking experiments demonstrate that XPC-RAD23B (Maltseva et al. 2007), as well as XPA (Wakasugi \& Sancar, 1999) show a high affinity to damaged DNA without binding directly to the lesion (Reardon \& Sancar, 2002). Reconstitution experiments with NER-deficient cells with all the different NER proteins in different order delivered contradictory results. Sugasawa et al. showed a fast repair rate when the cells where preincubated with XPC-RAD23B (Sugasawa et al. 1998). Preincubation of the damaged plasmids with XPA-RPA slowed down the repair velocity. Experiments from Wakasugi et al. however showed a more effective repair when damaged DNA was preincubated with XPA/RPA (Wakasugi \& Sancar, 1999).

\subsection{Overview of each XP protein and its role in GG-NER}

In Fig. 2, the different steps of the GG-NER mechanism are depicted. It is believed that XPC-RAD23B initiates the GR-NER by recognition of the damage (Fig. 2a, b) (Reardon \& Sancar, 2003; Sugasawa et al. 1998; Wakasugi \& Sancar, 1998). XPC ignores the lesion but binds to the ssDNA opposite to the lesion (Min \& Pavletich, 2007). In the case of UV lesions, the 
Table 1. Overview of the XP proteins involved in NER and TLS. ERCCX: Excision repair cross-complementing rodent repair deficiency complementation group X. Af: Archaeoglobus fulgidus, Dr: Danio rerio, Sa: Sulfolobus acidocaldarius, Ape: Aeropyrum pernix, Ta: Thermoplasma acidophilum, AAF-dG: N-(2'-desoxyguanosin-8-yl)-2-acetylaminofluorene, 6-4PP: 6-4PP, CPD: cyclobutane-pyrimidine dimer. PDB codes depicted in bold refer to NMR structures.

\begin{tabular}{|c|c|c|c|c|c|}
\hline Protein (gene) & Function & Protein size (aa) & Interaction partner & PDB code & DNA substrate \\
\hline XPA (XPA) & Damage verification & $31 \mathrm{kDa}(273)$ & $\begin{array}{l}\text { RPA, TFIIH, XPF-ERCC1, } \\
\text { DDB2, PCNA }\end{array}$ & $\begin{array}{l}\text { 1XPA } \\
\text { 5A39 (Rad14) } \\
\text { 5A3D }(\operatorname{Rad} 14)\end{array}$ & $\begin{array}{l}- \\
\text { cisplatin } \\
\text { AAF-dG }\end{array}$ \\
\hline XPB (ERCC3) & $3^{\prime}-5^{\prime}$ DNA helicase & $89 \mathrm{kDa}(782)$ & XPC, XPA, XPG, XPF & $\begin{array}{l}\text { 2FWR (Af) } \\
4 \mathrm{ERN}\end{array}$ & $\begin{array}{l}- \\
-\end{array}$ \\
\hline XPC-RAD23B (XPC) & Damage recognition & $\begin{array}{l}\text { XPC: } 106 \mathrm{kDa}(940) \\
\text { RAD23B: } 43 \mathrm{kDa}(409)\end{array}$ & $\begin{array}{l}\text { XPA,TFIIH, RAD23B, } \\
\text { UV-DDB2, }\end{array}$ & 2QSG (Rad4) & $\mathrm{CPD}$ \\
\hline XPD (ERCC2) & $5^{\prime}-3^{\prime}$ DNA helicase & $87 \mathrm{kDa}(760)$ & XPC, XPA, XPG, XPF & $\begin{array}{l}3 \mathrm{CRV}(\mathrm{Sa}) \\
4 \mathrm{~A} 15(\mathrm{Ta})\end{array}$ & $\begin{array}{l}- \\
\text { ssDNA }\end{array}$ \\
\hline XPE (UV-DDB1/2) & $\begin{array}{l}\text { Damage recognition } \\
\text { of UV lesions }\end{array}$ & $\begin{array}{l}\text { DDB1: } 127 \mathrm{kDa}(1149) \\
\text { DDB2: } 48 \mathrm{kDa}(428)\end{array}$ & XPC, RPA, XPA & $\begin{array}{l}\text { 3EI1 (Hs-Dr) } \\
4 \mathrm{~A} 08 \\
4 \mathrm{E} 5 \mathrm{Z}\end{array}$ & $\begin{array}{l}6-4 \mathrm{PP} \\
\mathrm{CPD} \\
\text { abasic lesion }\end{array}$ \\
\hline $\begin{array}{l}\text { XPF-ERCC1 } \\
\text { (ERCC4) }\end{array}$ & $5^{\prime}$-endonuclease & $\begin{array}{l}104 \mathrm{kDa}(916) \\
33 \mathrm{kDa}(297)\end{array}$ & TFIIH, XPA, ERCC1 & $\begin{array}{l}\text { 2A1J } \\
\text { 2KN7 }\end{array}$ & $\begin{array}{l}- \\
\text { ssDNA }\end{array}$ \\
\hline XPG (ERCC5) & $3^{\prime}$-endonuclease & $133 \mathrm{kDa}(1186)$ & XPA, TFIIH, PCNA, XPD & 4Q0W (Rad2) & dsDNA with ss overhang \\
\hline XPV (POLH) & Damage bypass & $78 \mathrm{kDa}(713)$ & PCNA & $\begin{array}{l}\text { 1JIH }(\operatorname{Rad} 30) \\
\text { 2R8K }(\operatorname{Rad} 30) \\
\text { 3MFI }(\operatorname{Rad} 30) \\
\text { 3MR3 }\end{array}$ & $\begin{array}{l}- \\
\text { cisplatin } \\
\text { CPD } \\
\text { CPD }\end{array}$ \\
\hline
\end{tabular}

recognition process by XPC-RAD23B is sustained by the UV-DNA damage-binding protein 2 (UV-DDB2) (Luijsterburg et al. 2010; Min \& Pavletich, 2007; Riedl et al. 2003; Volker et al. 2001). After this step, the general transcription factor TFIIH is recruited to the lesion site using the energy provided by the ATPase activity of XPB (Fig. 2c). Normally, TFIIH is involved in transcription by RNA polymerases I and II, but in the presence of DNA damage it is clearly recruited $5^{\prime}$ to the damage site (Hoogstraten et al. 2002). Two subunits of TFIIH, the ATP-dependent DNA helicases XPB and XPD, are needed for 'hooking up' TFIIH at the lesion site performing further unwinding and damage verification. It is believed that XPB opens the DNA and facilitates the binding of XPD to the DNA which verifies the chemical modification of the lesion (Scharer, 2013). In addition, XPD scans the strand with the lesion and both helicases are stalled when XPD encounters a bulky lesion (Li et al. 2015; Mathieu et al. 2013). In the next step, XPA and RPA (Fig. 2d, e) are thought to be recruited to the damaged site to form the PIC which is stabilized by the structure specific endonucleases XPG (Fig. 2e). Upon arrival of XPG to the PIC, XPC-RAD23B leaves the complex (Riedl et al. 2003; Wakasugi \& Sancar, 1998). Besides XPD, XPA might be involved in damage verification, however, the details of this event remain elusive (Naegeli \& Sugasawa, 2011; Tapias et al. 2004). The ssDNA-binding protein RPA now binds the undamaged strand, while TFIIH opens the duplex. XPA is then thought to recruit the structure specific endonuclease XPF-ERCC1 heterodimer (Li et al. 1995a; Tsodikov et al. 2007) and incision on both sites of the lesion takes place. The first incision 5' of the lesion is made by XPF-ERCC1 (Staresincic et al. 2009). Then, XPG cuts 3' to the lesion (Fagbemi et al. 2011) triggering the elimination of a 24-32 oligonucleotide containing the lesion (Fig. 2f) (Edenberg \& Hanawalt, 1972; Evans et al. 1997b; Ikegami et al. 1998). After that, DNA replication by the polymerases $\kappa / \delta / \epsilon$ takes place sustained by other factors (PCNA, RFC and RPA) (Ogi et al. 2010). Finally, the new synthesized DNA strand is mostly sealed by DNA ligase III/XRCC1. DNA ligase I is only recruited to sites of UV damage in proliferating cells (Fig. 2g) (Moser et al. 2001, 2007; Reardon \& Sancar, 2005; Wood, 1997). Table 1 gives an overview of the XP proteins, their function and size, their interaction partners as well as the PDB codes of solved structures associated to the DNA substrates.

\section{XPE (UV-DDB2)}

For the recognition of UV lesions such as 6-4PPs and CPD, the UV-DDB protein seems to promote binding of XPCRAD23B to the damaged site (Scrima et al. 2008). The UV-DDB protein, consists of the two subunits DDB1 (also called p127 with $127 \mathrm{kDa}, 1149$ amino acids) and DDB2 (called p48 with $48 \mathrm{kDa}, 428$ amino acids) (Fig. 3a). It shows a 100- to 1000-fold higher affinity to photolesions than XPC-RAD23B (Keeney et al. 1993; Takao et al. 1993). Both subunits are required for the activity of the complex (Hwang et al. 1998a; Keeney et al. 1993; Nichols et al. 1996). UV-DDB is known to be involved in the DNA damage recognition process of GG-NER (Wakasugi et al. 2002). The DDB2 subunit binds with 
preference to 6-4PPs but it also recognizes CPD lesions and it also binds abasic sites as well as DNA bubbles (Fujiwara et al. 1999). DDB1 is not involved in DNA binding. Mutation of the DDB2 subunit leads to a loss of function of the UV-DDB protein found in XP complementation group E (XPE) in patients (Chu \& Chang, 1988). XPE-deficient cells are shown to be defective in GG-NER (Hwang et al. 1999). Wakasugi et al. showed that UV-DDB rapidly accumulates in vivo independently of XPA and XPC at DNA damage sites after UV-irradiation (Wakasugi et al. 2002). Furthermore, they showed that UV lesions are mostly recognized by UV-DDB which then recruits XPA and XPC.

\subsection{Crystal structure of human XPE with 6-4PP damaged dsDNA}

Scrima et al. (2008) solved the crystal structure of the UV-DDB (human DDB1, HsDDB1 and the zebrafish DDB2 ortholog, DrDDB2) protein in complex with double-stranded DNA (dsDNA) containing the 6-4PP photolesion (Fig. 3b). In order to achieve damage recognition the UV-DDB2 protein inserts a $\beta$-hairpin into the minor groove of the DNA. In addition, the damaged dinucleotide is flipped out of the double helix and inserted into a binding pocket of the protein leading to a DNA kink of about $40^{\circ}$ at the lesion site. This destabilized conformation of the DNA might trigger the subsequent recruitment of XPC-RAD23B and further downstream factors. Due to the importance of DDB2, defective cells show a remarkable reduced CPD repair activity that gives rise to the XP-E phenotype (Hwang et al. 1998a; Tang et al. 2000).

\subsection{Crystal structure of human XPE with CPD damaged dsDNA}

Fischer et al. (2011) obtained insight into the molecular basis of CPD lesion recognition by solving the crystal structure of the UV-DDB protein in complex with CPD containing DNA. For obtaining the structure, residues creating crystal contacts in the apoprotein that prevented protein crystallization were mutated. Consistent with the structure of Scrima et al. (2008) the CPD lesion is held by the DDB2 WD40 propeller. The crystal structure shows that the lesion recognition takes place with the help of a $\beta$-hairpin ('finger') consisting of the residues Phe371, Gln372 and His373 (Fig. 3c). This $\beta$-hairpin inserts into the minor groove of the DNA duplex at the damage site and unwinds the duplex by $12.6^{\circ}$. Consequently the CPD lesion is extruded into an extrahelical, flippedout state. Finally, the DNA shows also a kink angle of about $45^{\circ}$ at the cis-syn CPD lesion site.

The UV-DDB protein is part of an ubiquitin ligase complex. The displacement of COP9 signalosome (CSN) from this complex by DDB2 substrate binding leads to ubiquitination of XPC and DDB2 (Groisman et al. 2003; Luijsterburg et al. 2007). This is thought to mediate the handover to XPC by stabilizing it, resulting in an increase of its affinity for damaged DNA, while the affinity of DDB2 to DNA containing a lesion is reduced (El-Mahdy et al. 2006; Sugasawa et al. 2005). Histones surrounding the lesion are ubiquitinated as well, which is suggested to slacken the nucleosome structure to promote recruitment of NER repair enzymes to the damage (Wang et al. 2006).

\subsection{Crystal structure of human XPE with an abasic lesion site in dsDNA}

Yeh et al. (2012) solved a dimeric crystal structure of UV-DDB (human DDB1 and DDB2) protein in complex dsDNA containing an abasic site (THF) (Fig. 3d). Each DDB2 subunit is bound to one double-stranded oligonucleotide. The DDB2 residues Asn360/Asn360 are located between the two DNA strands spanning two antiparallel $\beta$-strands ( $\beta$-wing) and giving rise to a 2 -fold symmetry axis of the dimer. The crystal structure shows that the residues on the leading $\beta$-strand and loop form contacts with the undamaged DNA strand and the residues on the loop and the retreating $\beta$-strand form contacts with the neighboring undamaged DNA strand. These contacts are supported by additional interactions of the N-terminal-helical domain of DDB2 ( $\alpha$-paddle) with the neighboring DNA-strand which lead to dimerization, explaining the high affinity to damaged DNA.

\section{XPC}

The human XPC protein is a polypeptide of 940 amino acids with a size of $106 \mathrm{kDa}$, forming a stable complex with the RAD23B protein ( $43 \mathrm{kDa}, 409$ amino acids). It is currently believed that XPC-RAD23B is responsible for the initial damage recognition with the exception of CPD lesions, where DDB2 is the first binding factor (Hey et al. 2002; Sugasawa et al. 2001). The complex is known to interact with several other proteins, e.g. XPA and TFIIH (Fig. 4a, b) (Araujo et al. 2001; Bernardes de Jesus et al. 2008; Cleaver et al. 2009). After binding, the protein recruits further downstream factors to the damaged site (Sugasawa et al. 1998). Biochemical assays show that the XPC-RAD23B complex binds with high affinity to different DNA lesions, e.g. 6-4PP and AAF-adducts (Batty \& Wood, 2000b; Sugasawa et al. 2002). The breakthrough came in 2001 when the Mullenders group was able to show that XPC might be the initial damage recognizer also for UV lesions. In the experiment, nuclei of living cells were irradiated with UV light at defined positions through a porous polycarbonate filter (Katsumi et al. 2001; Mone et al. 2001; Volker et al. 2001). The generated UV lesions could be detected by antibodies specific against CPDs and 6-4PPs. To identify which NER factors were recruited to these sites they were also visualized 


\section{journals.cambridge.org/qrb}

(a)

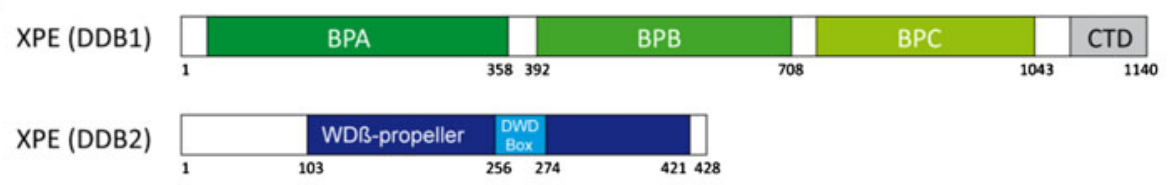

(b)

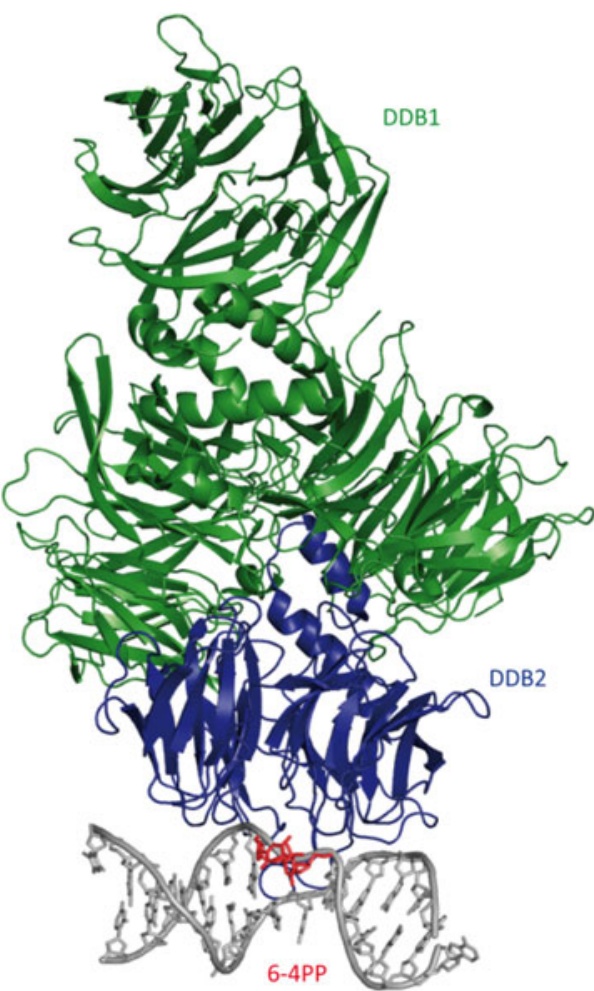

(d)

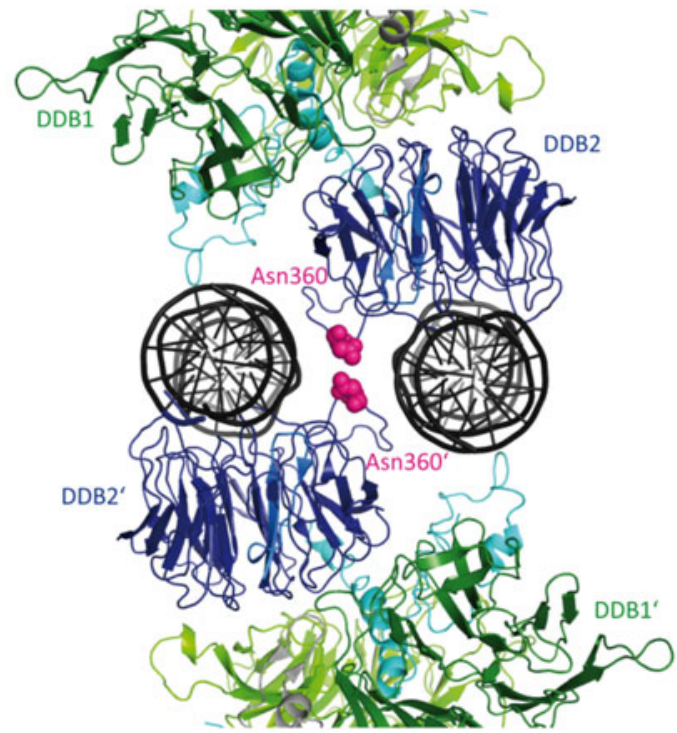

(c)

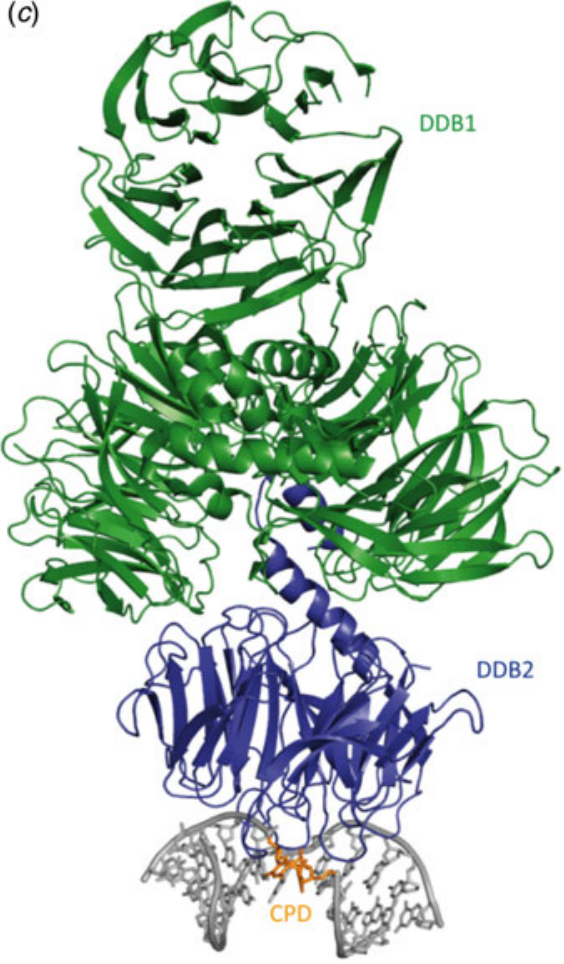

Fig. 3. Crystal structures of the human XPE protein (UV-DDB). (a) Schematic representation of the human UV-DDB protein (DDB1 and DDB2) with the different domains. (b) Crystal structure of the XPE protein in complex with 6-4PP damaged DNA (PDB code: 3EI1) (Scrima et al. 2008). DDB1 is depicted in green, DDB2 in blue, DNA in gray and the 6-4PP dinucleotide in red. (c) Crystal structure of XPE in complex with the CPD lesion (PDB code: 4A08) (Fischer et al. 2011). DDB1 is depicted in green, DDB2 in blue, DNA in gray and the CPD lesion in orange. (d) Crystal structure of the dimeric human UV-DDB in a complex with an abasic lesion (PDB code: 4e5z) (Yeh et al. 2012). DDB1 is depicted in green, DDB2 in blue, DNA in dark gray, DDB2 $\alpha$-paddle in cyan and the amino acid Asn360 in pink. 
(a)

(a)

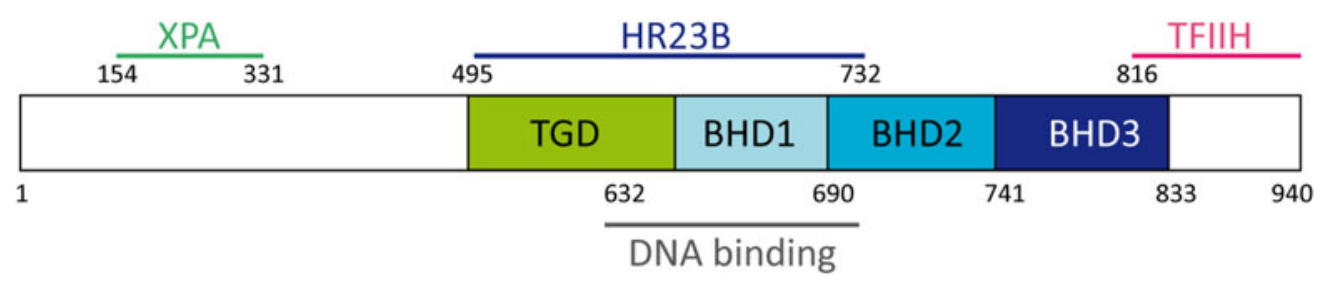

(b)

HR23B

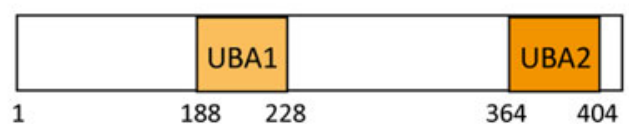

Fig. 4. Schematic representation of human XPC and RAD23B. (a) The TGD domain of XPC is depicted in green, the BHD1 domain in light blue, the BHD2 domain in blue and the BHD3 domain in dark blue. (b) The UBA1 and UBA2 domains of RAD23B are depicted in light orange and orange, respectively.

with an appropriate antibody. This experiment revealed that XPC colocalized with UV lesion sites in XPA-deficient cells, while XPA was not recruited in XPC-deficient cells (Volker et al. 2001). Thus, it was concluded that XPA needs the presence of XPC to be recruited to the damaged site and that XPC is the first factor being recruited to the damaged site. Further investigations pointed out that XPC is also required to unwind the DNA at the damaged site in order to recruit NER downstream factors (Katsumi et al. 2001; Mone et al. 2001). It has to be addressed that these experiments refer to the recognition of UV lesions. The general lesion recognition strategy adopted by XPC was established by a variety of experiments with different DNA lesions (Tapias et al. 2004). The helicase activity of XPD is not required for transcription but is indispensable for the NER process. The combined data show that XPC might be more structure specific than lesion specific. The XPCRAD23B complex is able to recognize ssDNA (Maillard et al. 2007) and DNA containing destabilizing lesions. Additionally it was shown, that the complex binds the DNA lesion in an asymmetric fashion (Sugasawa et al. 2002; Wakasugi \& Sancar, 1999). Interestingly, the complex also binds to 3-5 unpaired bases independently of the presence of damage. However, repair takes place only in the presence of DNA damage (Hess et al. 1997b; Sugasawa et al. 2001).

Hence, XPC might be a sensor for unpaired base pairs that occur in bubbles and loops and binds those in complex with RAD23B (Araki et al. 2001; Van der Spek et al. 1996) and Centrin2 (Araki et al. 2001). This would explain why 6-4PP, AAF-dG and intrastrand cisplatin crosslinks, which introduce a severe helical kink into the DNA structure (Lukin \& de Los Santos, 2006), are good substrates. On the other hand, CPDs are not recognized, possibly because they do not disturb the helical structure (Kusumoto et al. 2001; Reardon \& Sancar, 2003; Sugasawa et al. 2001). As mentioned previously the affinity of XPC-RAD23B to CPDs can be enhanced by introducing mismatches at the lesion site (Sugasawa et al. 2001).

\subsection{Crystal structure of yeast XPC (Rad4) in complex with a CPD lesion}

Min \& Pavletich, (2007) obtained the crystal structure of the yeast homolog of XPC-RAD23B (Rad4-Rad23, Fig. 5a) in complex with a CPD lesion in a mismatched situation with two thymidines (Fig. 5b). A shorter version of the protein (the DNA-binding domain) showing the same affinity to damaged DNA as the full length protein was crystallized. The crystal structure shows that Rad4 inserts a $\beta$-hairpin (beta hairpin domain 3, (BHD3)) into the destabilized DNA duplex, inducing the two damaged base pairs to completely flip out of the double helix (base flipping). A kink of $42^{\circ}$ is created which could be confirmed by atomic force microscopy (Hwang et al. 1999). The protein recognizes the expelled nucleotides of the undamaged strand through Van der Waals interactions with BHD1 and transglutaminase homology domain (TGD), while the two CPD-linked nucleotides are disordered in the structure and could not be resolved. The protein undergoes a conformational change during binding to damaged DNA (induced fit). The authors deduced from these findings that the lesions recognized by XPC must thermodynamically destabilize the Watson-Crick double helix in a manner that facilitates the flipping-out of two bases. The protein recognizes a weakened and distorted DNA helix without binding directly to the damage.

The structure, however, does not explain why the CPD damage alone, without a mismatch, is so efficiently repaired by NER. For UV lesion repair, additional damage recognition factors must exist. New experiments show that the UV-DDB protein plays a very important role and that this protein recruits the XPC-RAD23B protein to the UV-damaged sites (Fitch et al. 2003; Wakasugi et al. 2002). Also the 6-4PP lesion which is a better NER substrate than CPD (Mitchell \& Nairn, 1989), requires XPC-RAD23B as well as UV-DDB for recognition. See Section 2.

Camenisch et al. (2009) proposed a two-stage detection process for XPC that recognizes DNA lesions without involvement of a DNA-binding domain (BHD3). BHD1/BHD2 and a $\beta$-turn subdomain act as a damage sensor that scans the double helix 


\section{journals.cambridge.org/qrb}

(a)

Rad4

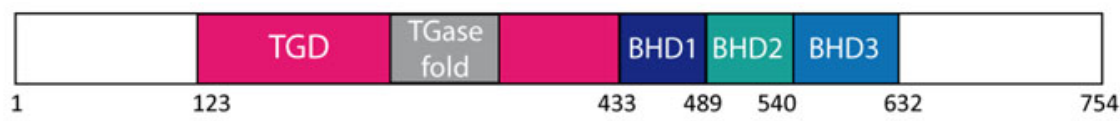

$\operatorname{Rad} 23$

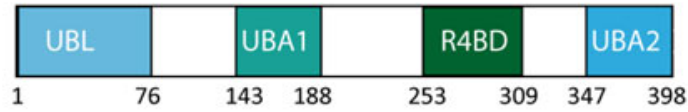

(b)

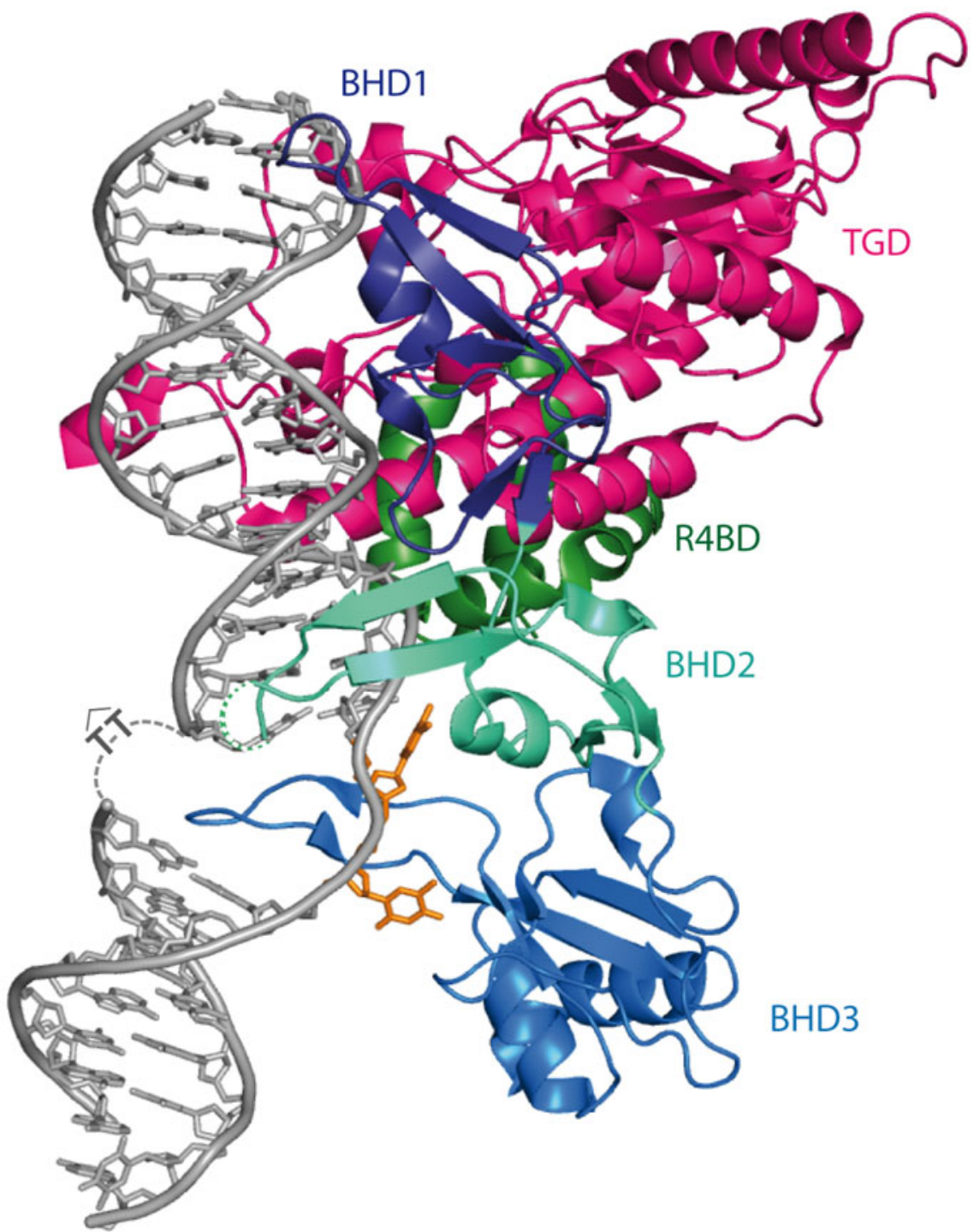

Fig. 5. (a) Schematic representation of Rad4 and Rad23. The TGD domain is depicted in pink, BHD1 in dark blue, BHD2 in cyan, BHD3 in blue and R4BD in green. (b) Crystal structure of the yeast Rad4-Rad23 in complex with a CPD damaged DNA (PDB code: 2QSG) (Min \& Pavletich, 2007). Same color code as in $(a)$. The extruded Ts in front of the CPD lesion are depicted in orange.

for unpaired bases, which forms a labile recognition complex. Subsequently, a stable recognition is formed through binding of BHD3 to the flipped out nucleotides in the undamaged strand across the lesion (Camenisch et al. 2009).

Chen et al. (2015) obtained the crystal structure of the yeast homolog of XPC-RAD23B (Rad4-Rad23) in complex with undamaged DNA using disulfide crosslinking. The crystal structure shows that Rad4 flips out normal nucleotide pairs like with damaged DNA. Therefore, structural discrimination of Rad4/XPC cannot play an important role for lesion recognition. The authors propose a 'kinetic-gating' mechanism for Rad4/XPC lesion recognition, which is controlled by two kinetic parameters (opening time and residence time). The weakened base stacking and hydrogen bonding within a lesion lead to a larger 
(a)

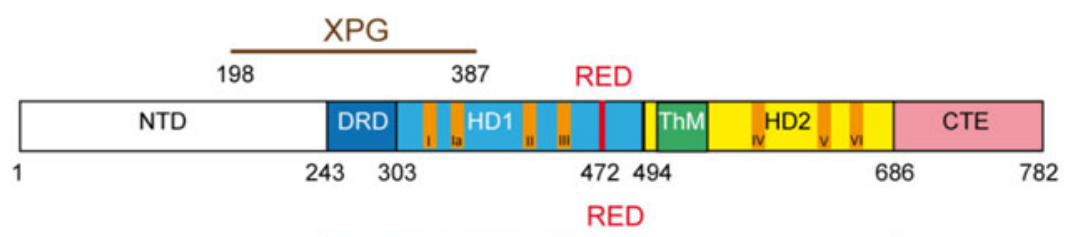

AfXPB

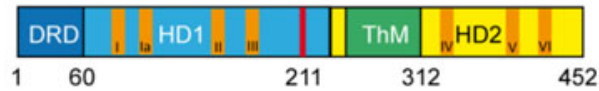

(b)

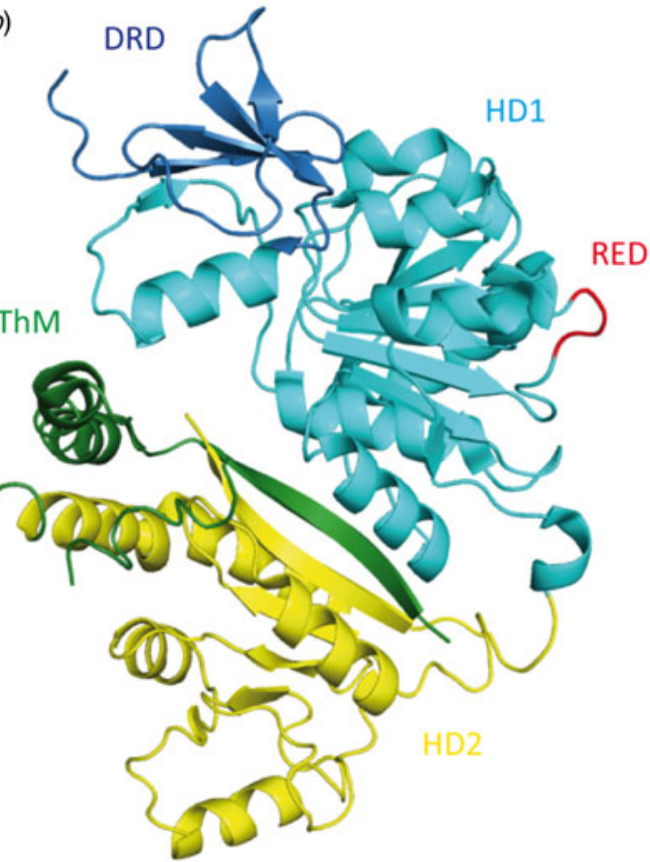

(c)

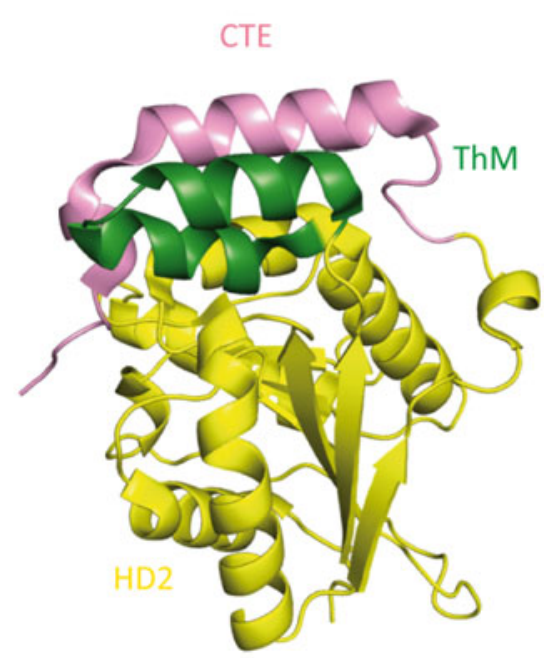

Fig. 6. (a) Schematic alignment of XPB and AfXPB showing the different domains: The DRD domain is depicted in blue, HD1 in light blue, HD1 in yellow, ThM in green and CTE (C-terminal extension) in pink. The conserved helicase motifs (Walker A motif I-VI) are depicted in orange. (b) Crystal structure of the AfXPB protein (PDB code: 2FWR). (Fan et al. 2006). Same color code as in (a). (c) Crystal structure of C-terminal domain of the human XPB protein (PDB code: 4ERN) (Hilario et al. 2013). Same color code as in (a).

opening time for damaged DNA than for undamaged DNA to form a stable recognition complex. Also, the residence time is larger for damaged DNA indicating that Rad4/XPC opens damaged DNA with a higher probability (Chen et al. 2015).

\section{XPB}

XPB (also called ERCC3) is a $3^{\prime}-5^{\prime}$ ATP-dependent DNA helicase and a subunit of the TFIIH complex necessary for transcription and DNA repair (Gillet \& Scharer, 2006; Lehmann, 2003; Schaeffer et al. 1993). Mutations in XPB lead to a 1000 -fold increase of the melanoma risk and neurological abnormalities because of a defective TFIIH function in NER (Lehmann, 2003). The human protein consists of 782 amino acids (89 kDa). NER helicases (XPB and XPD) all include conserved Rad51/RecA like ATPase domains called helicase domains 1 and 2 (HD1 and HD2), containing the ATPase and helicase motifs characteristic for superfamily 2 (SF2) helicases (Shin et al. 2003; Story \& Steitz, 1992). Furthermore, NER helicases consist of two accessory domains, which are responsible for transmitting the helicase domain changes upon binding to DNA. The ATPase activity of XPB is necessary during NER to anchor TFIIH to the lesion site (Abdulrahman et al. 2013; Coin et al. 1998; Dubaele et al. 2003; Oksenych et al. 2009). Its helicase activity is, however, not needed for the repair process (Coin et al. 2007; Oksenych et al. 2009; Tirode et al. 1999).

\subsection{Crystal structure of Archaeglobus fulgidus XPB (AfXPB)}

Fan et al. (2006) determined the crystal structure of an A. fulgidus XPB homolog (AfXPB) with a sequence equivalent to residues 240-686 of the human XPB (Fig. 6b). The AfXPB structure is built up by two Rad51/RecA-like helicase domains, HD1 and HD2, containing seven conserved helicase motifs (Walker motif I, Ia and II-VI) in the middle of the polypeptide (Fig. $6 a$ ) 


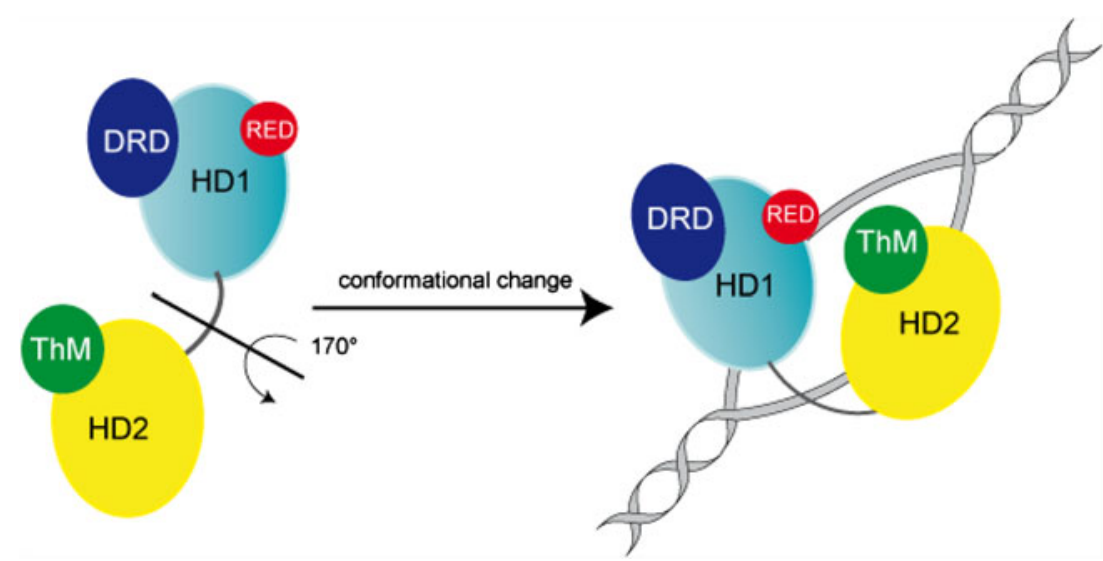

Fig. 7. Proposed model for binding of XPB to DNA (adapted from Fan et al. (2006)). The apo-protein is in an opened conformation. By binding to DNA, a rotation $\left(170^{\circ}\right)$ of the second helicase domain (HD2) together with the ThM domain, facilitated by HD1-mediated ATP hydrolysis, takes place and forms the closed and stable XPB-DNA complex. Same color code as in Fig. $6 a$.

(Fuss \& Tainer, 2011; Tuteja \& Tuteja, 1996). These domains use the binding and hydrolysis of ATP to induce conformational changes of the protein. Furthermore, the protein contains a DNA damage recognition domain (DRD), a unique RED motif (Arg-Glu-Asp) and a thumb domain (ThM). These domains are highly conserved and they are also found in the corresponding human protein. The structure suggests that the ATP hydrolysis provides the energy to induce a flip of about $170^{\circ}$ in the orientation of HD2 relative to HD1 after DNA binding (Fig. 7). This conformational change brings the RED domain and the ThM domain in close vicinity and stabilizes TFIIH on the DNA by inserting a wedge (Glu473) into the double strand, gripped by the ThM domain. The motion might be important for melting the DNA duplex and anchoring TFIIH (Coin et al. 2007). Mutations in the RED and ThM domains as well as mutations in the ATPase domain diminish the helicase activity, suggesting that these three domains ensure the correct recruitment of TFIIH to the damaged site.

\subsection{Crystal structure of human XPB}

Hilario et al. (2013) successfully solved the crystal structure of the C-terminal fragment of human XPB (residues 494-782) containing the helicase domain 2 (HD2), the thumb-like domain (ThM) and the C-terminal extension (Fig. 6c). They investigated the structural basis for the role of the C-terminus of XPB in transcription and DNA repair. Because of lack of electron density in the structure, only the positions of the residues 502-730 could be determined. The observed structure consists of a globular domain containing a central sheet of seven parallel $\beta$-strands sandwiched by three $\alpha$-helices on one side and two $\alpha$-helices on the other (Fig. 6c). The C-terminal extension (residues 670-730) is built up by two $\alpha$-helices linked by a loop and a $\beta$-strand, which forms the edge strand of the seven-stranded central sheet, and an unstructured tail that possibly extends to the $\mathrm{C}$-terminus. The ThM domain and one $\alpha$-helix of the C-terminal extension are located at the top of the central sheet. Thus, the recruitment of TFIIH to the damage site is an active process controlled by the ATPase motif of XPB. This suggests that this subunit acts as an ATP-dependent hook that stabilizes the binding of the TFIIH to damaged DNA (Hilario et al. 2013). In fact, a mutated ATPase activity of XPB abolishes the NER activity (Guzder et al. 1994; Sung et al. 1988). Recruiting TFIIH to the damage site by the ATPase activity of XPB may reorganize the protein-DNA complexes in order to allow new protein-protein or protein-DNA contacts to happen.

\section{XPD}

The XPD (also called ERCC2) protein with a size of $87 \mathrm{kDa}$ (760 amino acids) is known to be involved in transcription and DNA damage repair. It is a key subunit of the TFIIH complex and acts as an ATP-dependent 5' $-3^{\prime}$ DNA helicase that belongs to the superhelicase 2 family (SF2) proteins (Araujo et al. 2000; Coin et al. 2007). The helicase activity of XPD is not required for transcription but is indispensable for the NER process (Winkler $e$ t al. 2000). The TFIIH complex interacts with other NER factors such as XPA, XPC, XPG and XPF-ERCC1 (Evans et al. 1997a; Gillet et al. 2005). Mutations in human XPD lead to three different inherited diseases: XP, the CS and TTD. XPD is thought to be responsible for the damage verification (Mathieu et al. 2010; Naegeli et al. 1993) before the recruitment of downstream NER factors to the lesion site occurs. This idea has been postulated based on the observation that the helicase activity of XPD becomes inhibited by the presence of DNA damage (Mathieu et al. 2010, 2013; Naegeli et al. 1992). 
(a)

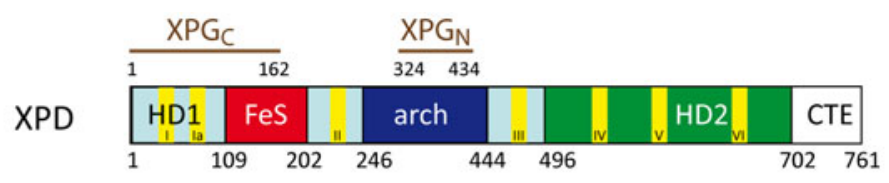

(b)

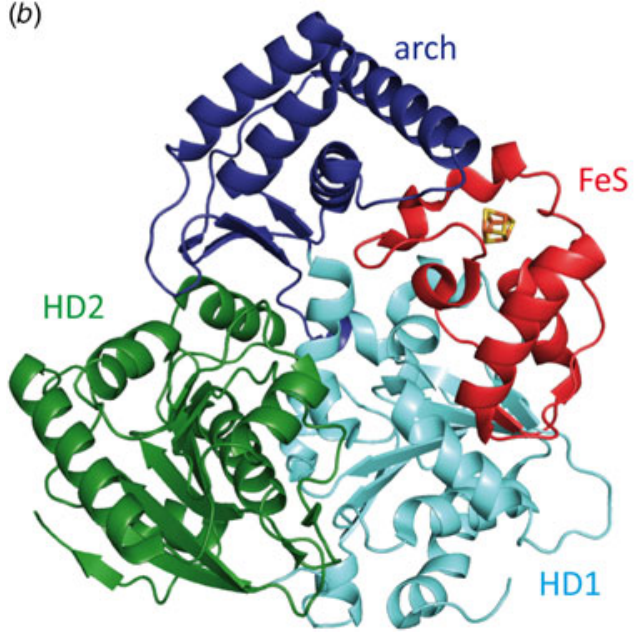

(c)

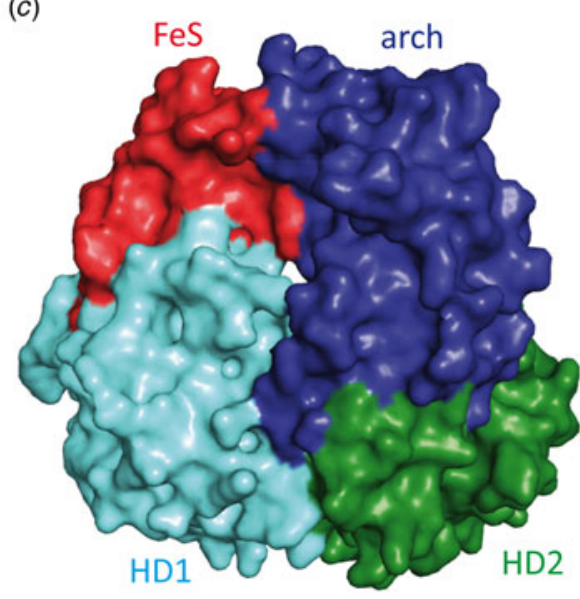

Fig. 8. (a) Schematic representation of human XPD (Fan et al. 2008). The protein interacts with $\mathrm{XPG}_{\mathrm{C}}$ (C-terminal domain of XPG) and $\mathrm{XPG}_{\mathrm{N}}$ (N-terminal domain of XPG) depicted in brown. (b) Crystal structure of SaXPD (PDB code: 3CRV) (Fan et al. 2008) with the HD1 domain (light blue) and the HD2 domain (green) form the ATP-binding interface. The arch domain is depicted in blue and FeS domain in red. The iron-sulfur cluster (4Fe4S) is depicted in orange and yellow. (c) Surface representation of SaXPD showing the tunnel formed by the different domains, which is large enough to pass through ssDNA.

\section{1 Crystal structure of Sulfolobus acidocaldarius XPD (SaXPD)}

Several crystal structures of the catalytic domain of XPD from different organisms (S. acidocaldarius (Fan et al. 2008) (SaXPD; Fig. 8), Thermoplasma acidophilum (Wolski et al. 2008) (TaXPD) and Sulfolobus tokodaii (Liu et al. 2008)) reveal a four domain organization: a domain harboring the $4 \mathrm{Fe} 4 \mathrm{~S}$ iron-sulfur cluster (FeS domain), an arch domain and two canonical Rad51/RecA like domains, the helicase domains HD1 and HD2 (Fig. 8a). The FeS domain is essential for the helicase activity of XPD.

The different domains form a tunnel that is large enough to harbor ssDNA (Fig. 8b, c) (Fan et al. 2008; Liu et al. 2008; Wolski et al. 2008). Fan et al. proposed a model of XPD binding to ssDNA (Fig. 9) (Fan et al. 2008). The iron-sulfur cluster is supposed to act as a molecular plough, which scans blocking damages by breaking hydrogen bonds (Lehmann, 2008; White, 2009). In this process, one strand of the duplex is supposed to be pulled through the internal channel with the help of the ATP-dependent motor domain, while damaged DNA will plug the channel (Fan et al. 2008; Liu et al. 2008; Mathieu et al. 2013; Pugh et al. 2012; Wolski et al. 2008). In this way, the protein undergoes a conformational change by closing the domain between the arch and the FeS motifs. The helicase domains HD1 and HD2 furnish the necessary flexibility for translocation (Fan et al. 2008).

Because the channel is not narrow enough to distinguish between damaged and undamaged bases 2008, Wolski et al. proposed that during the unwinding process single bases are analyzed through insertion of the DNA backbone into a neighboring binding pocket on the protein surface. Damaged bases would not fit into the pocket, which could be the signal that leads to blocking of the helicase activity (Wolski et al. 2008).

\subsection{Crystal structure of T. acidophilum (TaXPD) in complex with ssDNA}

Finally, in 2012 Kuper et al. successfully solved the crystal structure of TaXPD in complex with a ssDNA oligonucleotide (22mer), shedding light on the mechanism of polarity and translocation of the protein along the DNA (Kuper et al. 2012). At the same time Pugh et al. showed that the $5^{\prime}-3^{\prime}$ translocation polarity needs conserved residues in the HD1 and the FeS domains. They propose that the FeS domain provides a wedge-like feature enabling the duplex opening during unwinding (Pugh et al. 2012). 


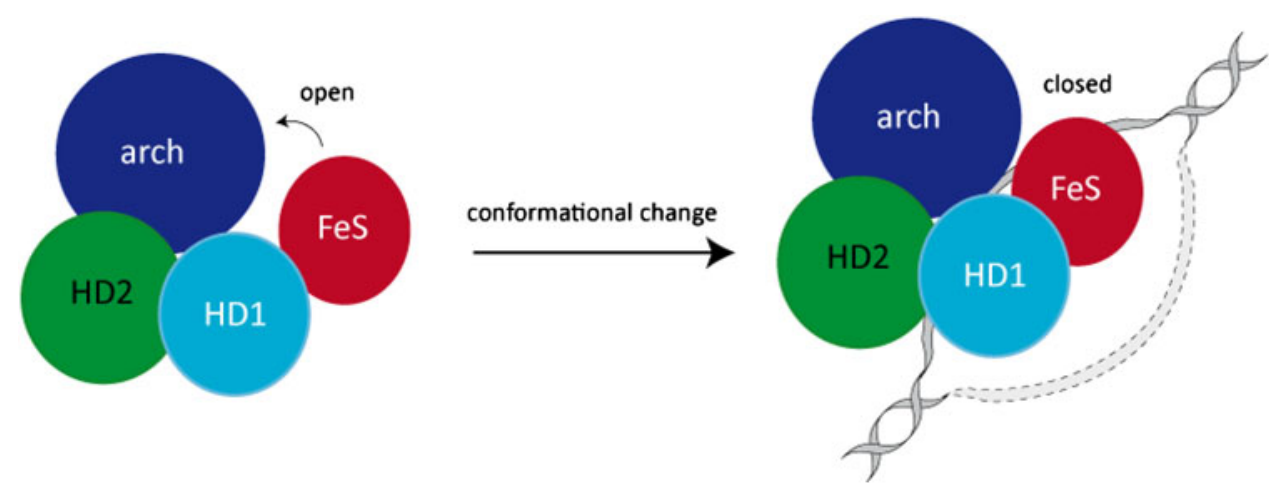

Fig. 9. DNA-binding model of SaXPD adapted from Fan et al. (2008). The HD1 domain is depicted in light blue, the HD2 domain in green, the arch domain is depicted in blue, the FeS domain in red and the DNA in gray. Upon binding to the DNA the protein undergoes a conformational change by closing the domain between the arch and the FeS domains.

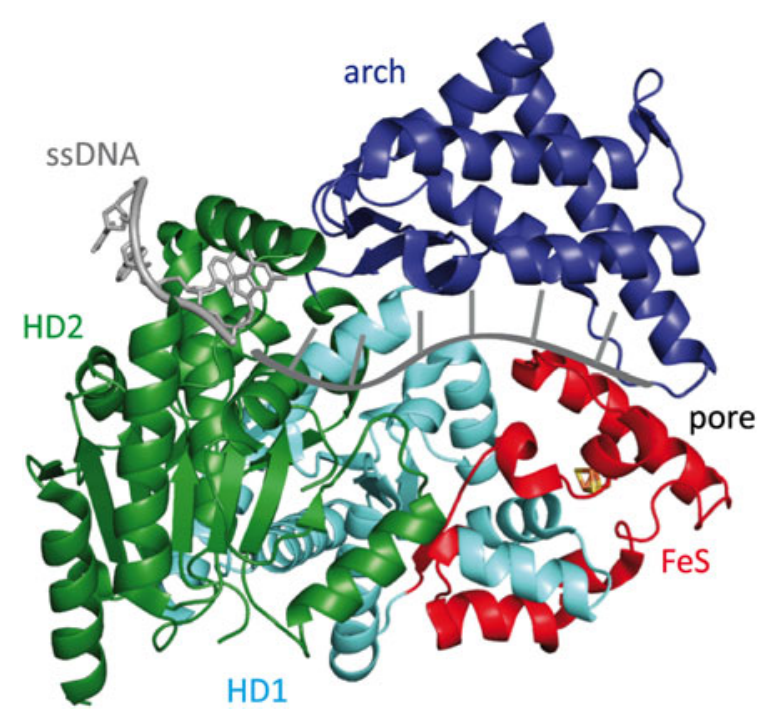

Fig. 10. Crystal structure of Thermoplasma acidophilum XPD (TaXPD) in complex with a $10 \mathrm{nt}$ ssDNA. The arch domain is depicted in dark blue, the FeS domain in red, the HD1 domain in cyan and the HD2 domain in green. The four bases (TACG), showing electron density, are depicted as gray sticks. The modeled ssDNA in the pore is schematically represented in gray. The modeled structure is adapted from Kuper et al. (2012).

The structure allowed the Kisker group to define the translocation path of the DNA substrate through the protein and to determine the DNA-binding domain (DBD) of TaXPD by mutational and biochemical analysis. Only four bases (TACG) of the oligonucleotide could be identified in the electron density. These bases are located in the cleft of the HD2 domain (Fig. 10). This domain was already predicted as a potential binding cleft by Wolski et al. (2008). The structure shows stacking of Trp549 with the adenine of TACG. Arg584 builds hydrogen bonds with N1 and N2 of the phosphate backbone of adenine and cytosine. Phe538 does not directly contact the DNA, but it is supposed to stabilize larger bases like adenine or guanine. A fourth residue Asp582 stabilizes Arg584 by hydrogen bonding to maintain it in position for DNA binding. The 5' end points away from the HD2 domain and the $3^{\prime}$ end points towards HD1 domain. Kuper et al. propose a model (Fig. 10) which shows how the ssDNA is situated and translocated in the protein.

\subsection{Proposed model of damage verification}

Based on these new data about XPD, Fuss and Tainer proposed an extended model of the damage verification process, the so-called 'bind-pry-unwind'-model: (Fuss \& Tainer, 2011) here XPB, XPD and CAK of the TFIIH complex are all considered to be essential for the coordination of damage recognition, verification, repair and signaling. In this model, the damage recognition proteins not only recruit the TFIIH complex and other NER factors to the damage site, but also fix the DNA at the same time. Kim et al. suggested that XPB facilitates the unwinding of the DNA duplex during transcription by distorting the 
DNA underneath the transcription bubble, which is fixed by the transcription factors and RNAP II (Kim et al. 2000). Similarly XPB could unwind and open the DNA. In that way, the damage verification step and the DNA unwinding could be linked. These findings are in accord with the low helicase activity of XPB and its strong conformational change upon binding to DNA (Fan et al. 2006). Furthermore, TFIIH can thereby position itself directly next to XPC-RAD23B or RNAP II, which establishes a common mechanism of how XPB may act in GG-NER, TC-NER and transcription. Through its short binding canal, XPB could place TFIIH vertically to the DNA and $5^{\prime}$ of the recognition protein. Then XPB could break the DNA strand, so that TFIIH bends it towards the DNA enabling XPD to bind about 22 base pairs away from the lesion on the damaged strand. Fuss and Tainer assume that the distance between XPB and XPD determines the size of the open DNA-bubble, corresponding to about 27 base pairs that are eliminated during NER. XPA catalyzes the release of CAK from the TFIIH complex (Coin et al. 2008). This step signals that the repair process can be continued and promotes the incision step. The XPD helicase unwinds the duplex until the 4Fe4S-cluster docks onto the damage and is blocked by it (Mathieu et al. 2010; Naegeli et al. 1993). Recent studies show that XPD exists in different conformations depending on the type of damage (Buechner et al. 2014). After the blockage, XPD and XPC-RAD23B anchor the TFIIH complex and build a platform for binding of ERCC1-XPF and XPG (Araujo et al. 2001).

Following this model RPA, XPA and XPG probably reach the lesion site independently and build together with TFIIH the pre-incision complex (Rademakers et al. 2003; Riedl et al. 2003; Volker et al. 2001; Wakasugi \& Sancar, 1998). Here, all NER factors, except ERCC1-XPF, are present and stably bound to the open DNA bubble.

Recently, the Kisker group showed by mutational analysis that the FeS domain of XPD is crucial for NER (Kuper et al. 2014). Furthermore, the successful repair process is dependent on the enzymatic activities of XPD which involves DNA binding, ATPase activity, helicase activity and the correct interaction with other TFIIH subunits. In 2013, the Naively group showed by uncoupling the DNA unwinding activity from the damage verification activity of XPD, that residues Tyr192 and Arg196 form a sensor pocket located ahead of the narrow central protein pore responsible for damage recognition. By mutating these two residues, the helicase and ATPase activities are not affected but the damage sensing during ATP-driven scanning movement along nucleic acid lattices fails and the ability of XPD to form stable DNA damage recognition intermediates is significantly reduced (Mathieu et al. 2013). The activity of XPD however is not relevant for transcription and DNA binding.

\section{XPA}

The XPA protein (xeroderma pigmentosum group complementation group A) consists of 273 amino acids (31 kDa) and can occur as either a homodimer or in complex with other NER proteins (Liu et al. 2005; Yang et al. 2002). The protein is constituted of several domains (Camenisch et al. 2006; Camenisch \& Nägeli, 2008): the N-terminal domain (XPA $4-97)$ includes the RPA34- and ERCC1-binding regions (He et al. 1995; Li et al. 1995a). The C-terminal domain (XPA 226-273) interacts with TFIIH (Camenisch \& Nägeli, 2008; Ikegami et al. 1998; Park et al. 1995a). The central domain (XPA98-219) is the minimal DBD (XPA-DBD) (Cleaver \& States, 1997; Kuraoka et al. 1996). The protein contains a zinc-finger binding domain (Cys105-X ${ }_{2}-$ Cys108- $\mathrm{X}_{17}-$ Cys126- $\mathrm{X}_{2}$-Cys129) (Hess et al. 1998). The $\mathrm{C}_{4}-$ zinc finger sustains the stability of the protein and plays a role in the interaction with RPA70 (Fig. 11a) (Ikegami et al. 1998; Kuraoka et al. 1996; Morikawa \& Shirakawa, 2000; Morita et al. 1996; Sugitani et al. 2014). Mutation of one or all zinc-binding cysteines leads to a loss of function of XPA and to an almost complete loss of function of NER (Li et al. 1995b; Mellon et al. 1987).

It has been demonstrated that XPA binds ssDNA, dsDNA and denaturated stretches of DNA in cooperation with RPA (Buschta-Hedayat et al. 1999; Missura et al. 2001; Wang et al. 2000; Yang et al. 2006). XPA shows binding affinity to irradiated DNA (Jones \& Wood, 1993; Liu et al. 2005), DNA containing bulky adducts and cisplatin lesions (Jones \& Wood, 1993; Liu et al. 2005), as well as to DNA duplexes containing loops and bulges (Camenisch et al. 2006). Camenisch et al. could show by mutational analyses that the residues Lys141 and Lys179 found on the surface of XPA next to the DNA-binding pocket are responsible for the sensing of DNA deformability as the common characteristics of damaged sites (Camenisch et al. 2006; Miyamoto et al. 1992). It was postulated that these two lysines interact with the DNA backbone, when XPA is in complex with RPA and kinked DNA (Read et al. 1993; Weir et al. 1993). Photocrosslinking experiments demonstrated that the mutated protein does interact with kinked DNA structures (Camenisch et al. 2006). This led to the assumption that the protein scans the DNA duplex for the presence of the kinked DNA structure with its positively charged pocket. The loop-rich domain of XPA was determined to be responsible for DNA binding. The ternary structure is stabilized by the zinc-finger domain (Miyamoto et al. 1992; Yan et al. 2002).

\subsection{Nuclear magnetic resonance (NMR) structure of the DBD of human XPA}

Ikegami et al. (1998) determined the NMR structure of the DBD of XPA (XPA98-219, called XPA-DBD) and they found that the protein contains $\alpha$-helices and $\beta$-sheets (Fig. 11b). The structure shows the presence of a positively charged (basic amino 
(a)



(b)

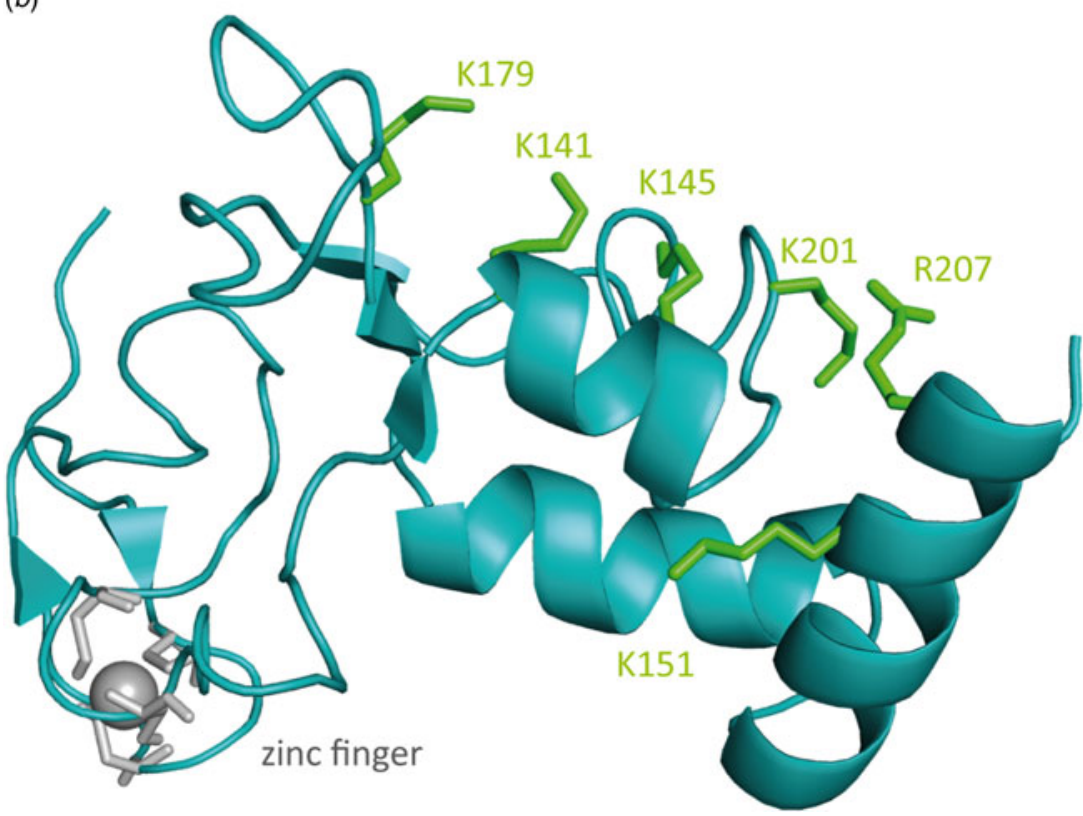

Fig. 11. (a) Schematic view of the human XPA protein with XPA-DBD (DNA-binding domain, $\mathrm{XPA}_{98-219}$ ) in cyan the zinc-finger domain in gray. The binding domains of XPA with other NER proteins are depicted in light blue for RPA34, green for ERCC1, dark blue for RPA70 and pink for TFIIH. (b) NMR-structure of the XPA-DBD (Buchko et al. 2001; Camenisch et al. 2006; Ikegami et al. 1998) (PDB code: 1XPA). Positively charged amino acids that build the cleft are depicted as green sticks. The zinc atom is shown in gray.

acids) cleft with the right dimension to bind dsDNA (Buchko et al. 1998, 2001). This positively charged cleft was speculated to interact with the negatively charged DNA backbone.

Sugitani et al. (2014) redefined the DBD of XPA. By extending the originally characterized XPD-DBD at its C-terminus by 20 amino acids $\left(\mathrm{XPA}_{98-239}\right)$, they improved the DNA-binding properties. The new construct with the additional critical basic residues and helical elements at its C-terminus was found to bind to DNA substrates with the same affinity as the full-length protein. The group reported, based on NMR data, that $\mathrm{XPA}_{98-239}$ contains the same globular core as XPA $\mathrm{X}_{98-219}$ and similarly undergoes a conformational change when binding to Y-shaped ss/ds-DNA junctions.

The rather small XPA protein interacts with a large number of other NER factors which supports its function as a scaffold protein for the assembly of the incision complex during repair (Gillet \& Scharer, 2006; Naegeli \& Sugasawa, 2011). Probably, XPA binds best to already prekinked DNA structures, which explains why XPA is able to bind defect Watson-Crick base pairing, created by mismatches, bubbles or three-way junctions (Bootsma \& Hoeijmakers, 1993; Buschta-Hedayat et al. 1999; Missura et al. 2001). These structures can form easily kinked DNA structures. XPA shows a slight binding preference to UV-damaged DNA and bulky adducts over undamaged DNA (Jones \& Wood, 1993; Robins et al. 1991; Thoma \& Vasquez, 2003). Similarly to XPC, XPA recognizes 6-4PP lesions but not CPDs (Jones \& Wood, 1993). CPD might block the bending of major grooves because of its stiff four-membered ring which points into the major groove. XPA shows a high affinity to DNA containing aromatic adducts and cisplatin crosslinks. Cisplatin crosslinks also kink the DNA structure. The damage recognition capability of XPA increases with RPA (Jones \& Wood, 1993; Li et al. 1995a; Mellon et al. 1987) and ERCC1 (Nocentini et al. 1997; Saijo et al. 1996). XPA does not bind ssDNA, in agreement with the observed size of the positively charged cleft able to fit dsDNA (Buchko et al. 1998; Ikegami et al. 1998). For single-base bulky adduct lesions such as AAF-dG, it is unclear to which extent they prekink the duplex. Bulky adducts can increase the local conformational flexibility of DNA (Isaacs \& Spielmann, 2004). XPA might employ a DNA flexibility scanning mechanism to create a kink, which could be stabilized by intercalation of the aromatic ring into the duplex and may be the secret behind the broad substrate 
(a)

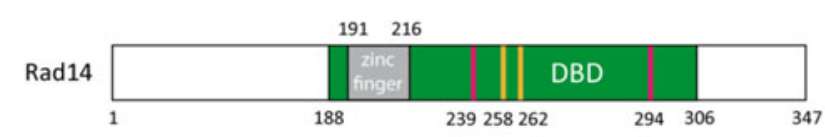

(b)

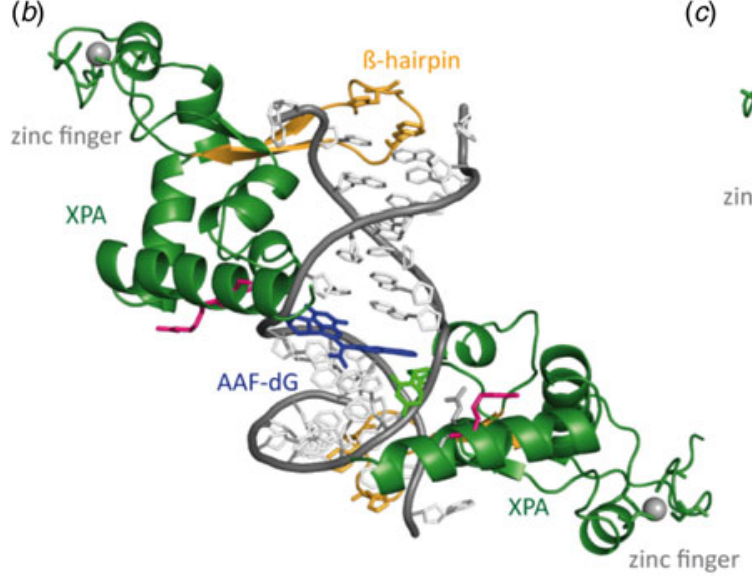

$(c)$

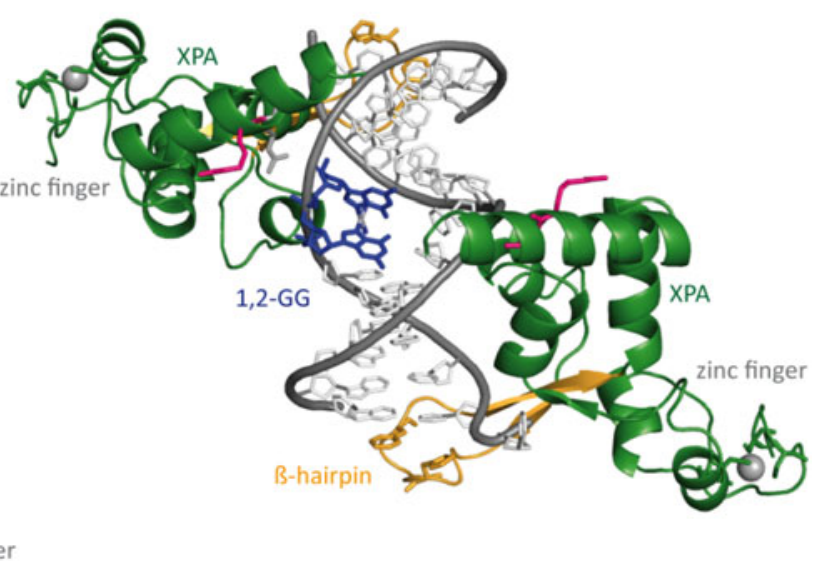

Fig. 12. (a) Schematic sequence of Rad14 with the DBD depicted in green, the zinc-finger domain in gray and the residues interacting with the DNA in orange and pink. (b) Crystal structure of Rad14 in complex with AAF-dG crosslinked DNA (PDB code: 5A3D) (Koch et al. 2015). Same color code as in (a). The AAF-dG residue is depicted in dark blue. (c) Crystal structure of Rad14 in complex with 1,2-GG cisplatin (PDB code: 5A39) (Koch et al. 2015). Same color code as in (a). The 1,2-GG cisplatin crosslink is depicted in dark blue.

promiscuity of NER. Koch et al. could obtain two crystal structures of Rad14 with a bulky lesion, which confirm this hypothesis (Koch et al. 2015).

\subsection{Crystal structures of Rad14 with AAF-dG and cisplatin containing dsDNA}

Recently, Koch et al. (2015) solved two crystal structures of the yeast homolog of XPA (Rad14) in complex with AAF-dG and 1,2-GG cisplatin containing DNA (Fig. 12b,c). The DBD of the protein (residues 188-306) was crystallized with damaged DNA (Fig. 12a). The structures allow us to uncover the molecular mechanism of XPA interacting with damaged DNA and are consistent with previous biochemical data showing the binding of XPA to kinked DNA structures (Buschta-Hedayat et al. 1999; Camenisch et al. 2006). The protein assumes an overall $\alpha / \beta$-fold quite similar to its human homolog (Ikegami et al. 1998; Koch et al. 2015). Comparable with Rad4, Rad14 does not bind the lesion directly; instead it recognizes a weakened DNA duplex structure (Min \& Pavletich, 2007). By the binding of two Rad14 proteins to the duplex, the DNA undergoes a sharp kink of $70^{\circ}$ at the lesion site and single stranded regions are formed above and below the $13 \mathrm{mer}$ binding motif. Through insertion of a $\beta$-hairpin (His258 and Phe262) from each protein (acting like 'fingers') exactly six base pairs away from the lesion, a 13mer recognition motif is generated. Another domain composed of helix $\alpha 7$ ('thumb' containing Arg234 and Arg239) interacts with the DNA backbone close to the lesion, so that DNA bending takes place into the major groove. The lesion is located inside the 13 mer duplex instead of being flipped out. Because of the relatively few interactions between Rad14 and the duplex, the protein might preferably bind already pre-kinked DNA structures (Camenisch et al. 2006). The 2:1 complex can coordinate contacts between TFIIH, DNA and RPA and recruit ERCC1-XPF (Li et al. 1995a; Park et al. 1995b; Tripsianes et al. 2007).

\section{XPF-ERCC1}

The human DNA repair endonuclease XPF (gene called ERCC4) is a protein of 916 amino acids (104 kDa) (Brookman et al. 1996). It forms a stable ERCC1-XPF heterodimer enzyme complex that participates in DNA repair and DNA recombination (Sijbers et al. 1996; Tsodikov et al. 2005). ERCC1 is a protein of 297 amino acids ( $32.5 \mathrm{kDa}$ ) that mediates DNA-protein and protein-protein interactions. The XPF-ERCC1 complex cuts specific structures near an ss/dsDNA junction at the 5 '-end of single stranded damaged DNA strand and hence makes the first incision in the NER process. Its nuclease activity is absolutely essential in the NER process (de Laat et al. 1999; Sijbers et al. 1996). In the complex, XPF provides the endonuclease active site and is involved in DNA binding and establishing additional protein-protein interactions. XPF-ERCC1 is known to be the last 
(a)
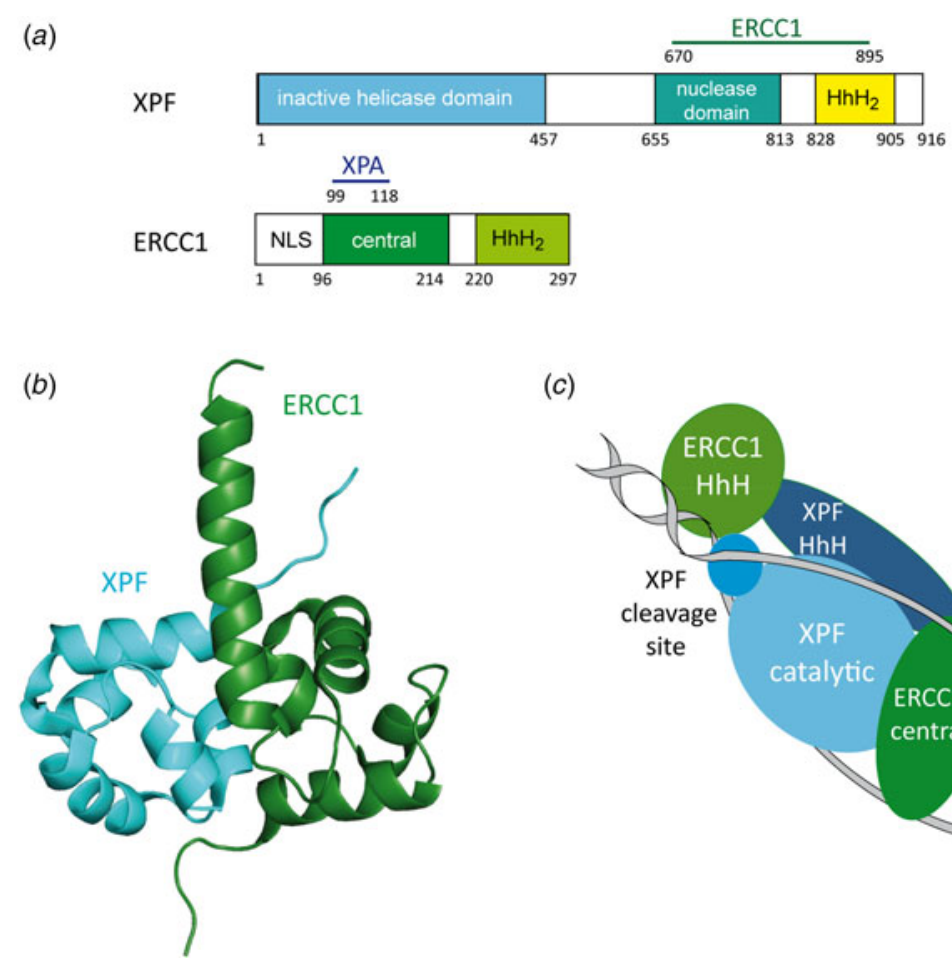

(c)

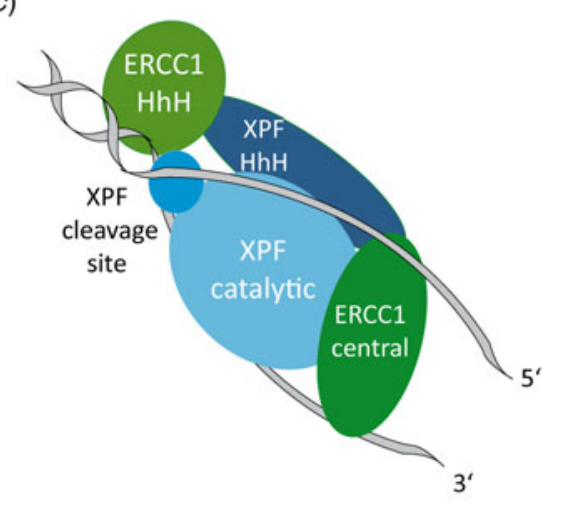

Fig. 13. (a) Structural domains of the human XPF and ERCC1 proteins. XPF interacts with ERCC1 (residues 670-895) depicted in green. The inactive helicase domain is depicted in light blue, the nuclease domain in cyan and the $\mathrm{HhH}_{2}$ domain in yellow. ERCC1 interacts with XPA (residues 99-118) depicted in dark blue. The central domain is depicted in green and the $\mathrm{HhH}_{2}$ domain in light green. (b) Structure of the human XPF-ERCC1 heterodimer (PDB code: 2A1J) (Tsodikov et al. 2005) with ERCC1 depicted in green and XPF depicted in light blue. $(c)$ Model of the XPF-ERCC1 complex binding to a splayed DNA substrate (depicted in gray). The ERCC1 central domain and $\mathrm{HhH}$ domain are depicted in green. XPF, XPF cleavage site and HhH domain are depicted in light blue.

factor joining the NER complex before dual incision takes place (Riedl et al. 2003; Volker et al. 2001; Wakasugi \& Sancar, 1998). Evidence exists that it is recruited by XPA (Fig. 13a) (Li et al. 1994, 1995a; Park \& Sancar, 1994; Saijo et al. 1996).

\subsection{Crystal structure of human XPF-ERCC1}

Tsodikov et al. (2005) solved the crystal structure of the minimal dimerization domains of the human XPF and ERCC1 (Fig. 13b). The crystallized domain shows a similar endonuclease activity compared to that of the full-length complex. Both protein domains exhibit double helix-hairpin-helix motifs $\left(\mathrm{HhH}_{2}\right)$ related by a pseudo-2-fold symmetry axis (Tripsianes et al. 2005). The $\mathrm{HhH}_{2}$ motifs are known to be ds- as well as ss-DNA-binding motifs (Newman et al. 2005; Singh et al. 2002). Both C-terminal $\mathrm{HhH}_{2}$ domains of XPF and ERCC1 are essential and sufficient for a stable heterodimer formation (de Laat et al. 1998). XPF might play a role as a scaffold protein, allowing proper folding of the ERCC1 domain. All $\mathrm{XPF}$ family members contain a catalytic domain comprising the active site motive $\left(\mathrm{GDX}_{n} \mathrm{ERKX}_{3} \mathrm{D}\right)$ and they need a divalent cation for their nuclease activity (Nishino et al. 2003; Sijbers et al. 1996).

\subsection{NMR structure of C-terminal human XPF in complex with sSDNA}

Das et al. (2012) solved the NMR structure of the C-terminal domain of the human XPF protein (residues 823-905) in complex with a 10-nucleotide ssDNA fragment. In earlier NMR studies of the apo-protein, the group showed that the XPF homodimer complex is more stable than the XPF-ERCC1 heterodimer complex (Das et al. 2008). The structure shows that a positively charged region of one $\mathrm{HhH}$ domain interacts with the ssDNA phosphate backbone. The central guanine (G5) is extruded from the duplex and inserted into a pocket formed by residues from both HhH motifs of XPF (Das et al. 2008; Tripsianes et al. 2005). This cavity offers a large interaction surface area for the protein with the DNA. The DNA forms a right-handed structure binding to the protein, which mainly interacts with the ssDNA phosphate backbone (Fig. 14). In addition, the protein interacts with three bases: thymidine3 (His857), thymidine4 (Ser875, Ile876) and G5 (Leu877, Gly878 and Asn879). Combined with previous data (Tripsianes et al. 2005) the group proposes a binding model of XPF-ERCC1 to ss/ dsDNA junctions (Das et al. 2012). They modeled the XPF-ERCC1 complex bound to a splayed-arm DNA substrate showing 


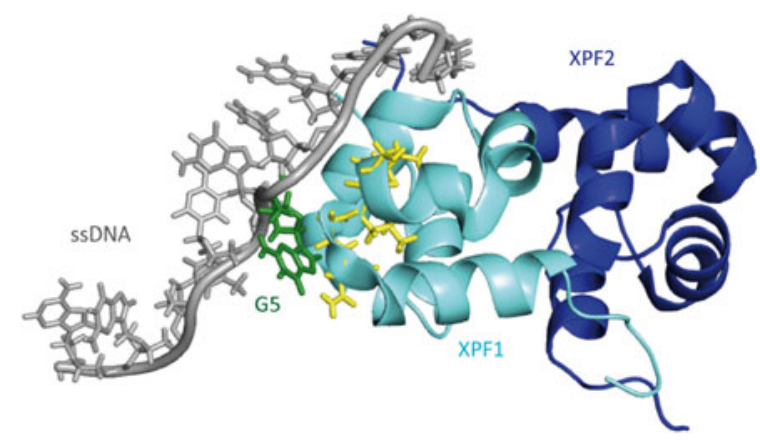

Fig. 14. NMR structure of the C-terminal domain of human XPF in complex with an ssDNA fragment (PDB code: 2KN7) (Das et al. 2012). The first XPF (XPF1) protein is depicted in light blue showing the interacting residues with the DNA in yellow. The second XPF (XPF2) protein is depicted in light blue. The central guanine (G5) is depicted in green.

that the conserved $\mathrm{HhH}$ domain of ERCC1 contacts the phosphate backbone of dsDNA in the minor grove with its two hairpins $\mathrm{H} 1$ and $\mathrm{H} 2$ while the XPF $\mathrm{HhH}$ domain stabilizes the ssDNA via interactions with a $5^{\prime} / 3^{\prime}$ polarity (Fig. 13c). The damaged strand gets cleaved by the catalytic residues of the XPF nuclease domain and the ERCC1 central domain connects with XPA and ssDNA on the NER complex (de Laat et al. 1998).

\section{XPG}

XPG (gene called ERCC5) is a single-stranded structure-specific DNA 3'-endonuclease involved in NER. It belongs to the family of FEN-1 endonucleases (Flap endonuclease) (Lieber, 1997). The human protein consists of 1186 amino acids (133 $\mathrm{kDa}$ ) (O'Donovan et al. 1994b) and it interacts with several other NER proteins (Fig. 15). Mutations in this gene cause the XP-G phenotype, characterized by hypersensitivity to UV light and increased susceptibility for skin cancer development following UV exposure. Furthermore, it can lead to the CS characterized by severe growth defects and mental retardation (Constantinou et al. 1999). The XPG protein cleaves DNA near junctions of dsDNA to ssDNA with a defined polarity moving $3^{\prime}-5^{\prime}$ away from the junction. It has been observed that XPG needs a duplex opening of more than five base pairs for efficient cleavage (Evans et al. 1997a). The protein is known to interact with XPB, XPD, RPA and PCNA (Feltes \& Bonatto, 2015; Iyer et al. 1996). XPG is needed for the proper recruitment of XPF-ERCC1 to the preincision complex. Once the $5^{\prime}$-incision is made by the XPF-ERCC1 nuclease, XPG becomes fully active (Staresincic et al. 2009). Despite this knowledge, the exact mechanism of substrate recognition by XPG is still unclear.

The human protein possesses a globular structure like the FEN-1 endonuclease (Hosfield et al. 1998; Hwang et al. 1998b). It contains an N-terminal domain and an I-region linked by a 600 residue long spacer region (Dunand-Sauthier et al. 2005; Hohl et al. 2007). The N-terminal and the I-region are evolutionary conserved among similar endonucleases (T4 RNaseH, Taq Polymerase). The spacer region is not involved in catalysis. It is responsible for proper DNA cleavage and for the recruitment and positioning of XPG to the lesion site (Constantinou et al. 1999; Dunand-Sauthier et al. 2005; He et al. 1995; Thorel et al. 2004). It is also known to interact with RPA and TFIIH. The protein contains a D1 box (residues 184-210) and a D2 box (residues 890-984) which are evolutionary conserved (Dunand-Sauthier et al. 2005; Houle \& Friedberg, 1999). One cation is required for the endonuclease activity in the active site. The protein shows a higher affinity for $\mathrm{Mn}^{2+}$ than for $\mathrm{Mg}^{2+}$ and uses the more abundant one for catalysis (Hohl et al. 2007; Iyer et al. 1996). Two residues in the active site (Glu791 and Asp812) coordinate the divalent cations (Constantinou et al. 1999) (light blue sticks in Fig. 15). The protein incises flap DNA and bubbled DNA structures with a defined polarity (Evans et al. 1997b; Hohl et al. 2003; O'Donovan et al. 1994a; Tsutakawa et al. 2011).

\subsection{Crystal structure of the yeast XPG (Rad2) in complex with dsDNA}

To understand the mechanism of DNA binding by XPG Mietus et al. (2014) solved in 2014 the crystal structure of the catalytic core of the Saccharomyces cerevisiae homolog of XPG (Rad2- $\Delta$ SC, Fig. 16a) in complex with four different DNA substrates. For crystallization a XPG variant missing the mostly disordered spacer residues 111-730 between the two sequence segments $\mathrm{N}$ and I of the nuclease domain was used. The double-stranded oligonucleotides (12-15 bp) were designed with single-stranded overhangs constructed with one to six adenines or thymidines. In the crystal structure two Rad 2 proteins bind to one DNA substrate with a single-protein molecule covering $13 \mathrm{bp}$ of the double-stranded portion. Rad 2 utilizes 


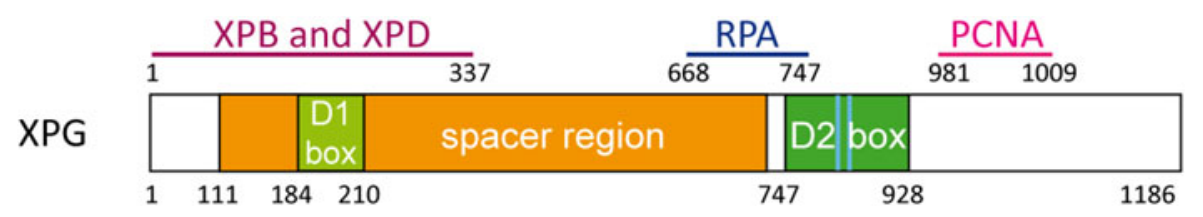

Fig. 15. Schematic representation of human XPG with its different domains and the region interacting with other NER proteins. The D1 box is depicted in light green, the D2 box in green and the 600 aa spacer region in orange. The XPB and XPD interacting region is highlighted in purple, RPA interacting region in dark blue and the PCNA interacting region in pink. Glu791 and Asp812 in the active sites are depicted as light blue bars.

(a)

Rad2

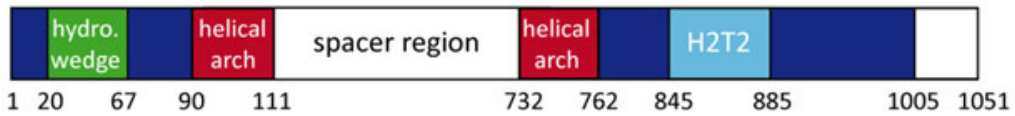

(b)

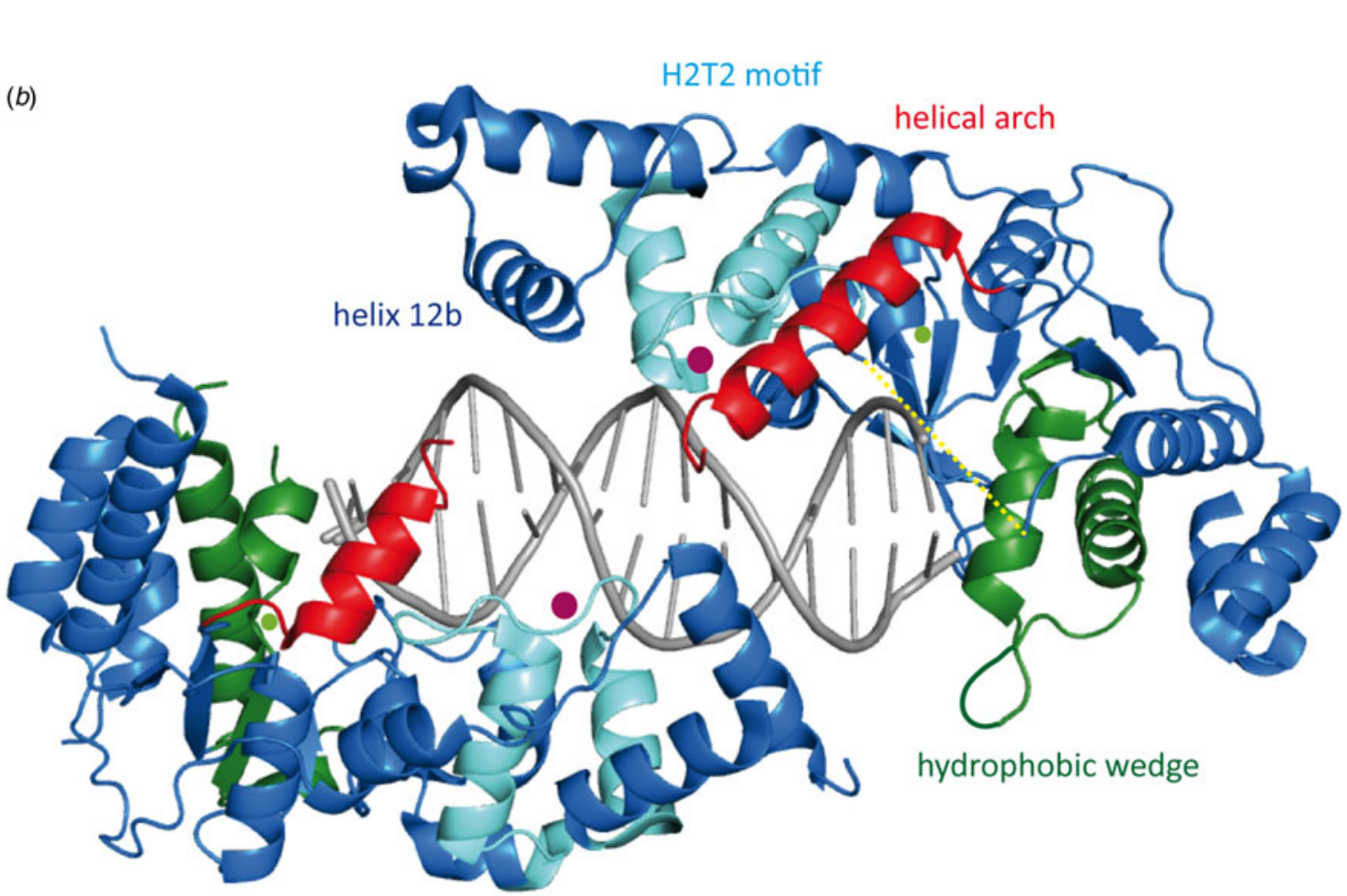

Fig. 16. Crystal structure of the Rad2-DNA complex (PDB code: 4Q0W) (Mietus et al. 2014). (a) Schematic representation of the protein. The hydrophobic wedge is depicted in green, the helical arch in red, the H2TH domain in light blue and the rest of the crystallized structure in dark blue. (b) Structure of Rad2 with dsDNA. Same color code as in (a). Calcium is depicted in light green and potassium in purple. The helix 12b is named as referred by Tsutakawa et al. (2011). The spacer region omitted in the crystal structure is depicted as a yellow dashed line.

three structural domains to recognize the double-stranded portion of the DNA but it does not specifically recognize the singlestranded portion of the duplex. The structures reveal that the protein recognizes a single 5 '-nucleotide of the single-stranded portion of the DNA and a 3'-phosphate group of the ds/ssDNA junction. The helix two turn helix (H2TH) motif including a Rad2-specific $\alpha$-helix 12b and a hydrophobic wedge, which binds the first base pair of the double-stranded portion of the DNA, is responsible for binding to DNA. The helical arch may assume a different structure in Rad2 because its active site is more accessible compared with related enzymes such as FEN1 and EXO1 (Mietus et al. 2014). This feature allows the protein to form a gap and create an exit route from the active site. As expected, the catalytic core of Rad2 is quite comparable with other flap nucleases (Orans et al. 2011). The protein has an oblong shape with its active site situated in the middle. A twisted central $\beta$-sheet composed of seven strands flanked by $\alpha$-helices build the central core of the protein (Fig. 16b). Gln37 forms a hydrogen bond with the base of the cleaved strand and represents an important residue of substrate recognition by Rad2. The $\mathrm{H} 2 \mathrm{TH}$ module is responsible for the key protein-DNA interactions through its Rad2-specific helix $\alpha 12 \mathrm{~b}$ and the hydrophobic wedge contacting the ss/dsDNA junction. 


\section{XPV}

The repair of lesions by NER is a powerful method to clean the genome from the plethora of lesions that are generated daily. NER is hence the prime pathway that allows cells to cope with DNA damage. Because lesions can occur at any time in cellular DNA, even when the NER complex cannot assemble properly, e.g. while the cell is undergoing cell division, a second system has evolved that allows cells to cope with lesions. This system does not repair lesions but is able to give cells the ability to tolerate lesions, so that repair can be shifted to later times. This lesion tolerance process (called TLS) requires the action of special lesion tolerance polymerases. Among them the polymerase $\eta$ (XPV) is of prime importance, because it provides tolerance of dinucleotide lesions such as CPDs and cisplatin adducts, which are the prime repair targets for NER. XPV (Polymerase $\eta$ ) is a Y-family DNA polymerase responsible for TLS enabling replication through bulky DNA adducts like cisplatin, UV-induced CPDs and 6-4PP as well as acetylaminofluorene adducts and oxidative lesions (like 8-oxo-G) (Alt et al. 2007; Biertumpfel et al. 2010; Haracska et al. 2000; Reissner et al. 2010; Schorr et al. 2010b; Silverstein et al. 2010a, b). The human protein consists of 713 amino acids with a size of $78 \mathrm{kDa}$ (Masutani et al. 1999a). Indeed, mutation in the XPV gene leads to just another form of XP called the variant type also associated with a high risk of developing skin cancer (Johnson et al. 2000; Lehmann et al. 1975; Masutani et al. 1999b). Lesion tolerance, however, has a major drawback. Because the polymerases are able to read through lesions they also have a strongly reduced replication fidelity, which gives rise to mutations. That is why repair is always the first and preferred defense pathway.

\subsection{Crystal structure of the yeast XPV (Rad30) protein}

Kondratick et al. (2001) solved the crystal structure of the catalytic core (1-513 amino acids) of the S. cerevisiae apo-enzyme (Fig. 17b). The catalytic core possesses the same bypass activity as the full-length protein (1-632 amino acids). The structure shows that the polymerase possesses a right-hand shape built up by four domains: thumb, fingers, PAD-domain (polymerase-associated domain also named 'little fingers' (LF)) and the palm domain (Fig. 17a). Characterized by a wide open and possibly flexible active site, the polymerase is able to replicate over bulky dinucleotide lesions, however, at the cost of misincorporation and only a low processivity in contrast to high-fidelity polymerases. Because of the helix deforming action of lesions like intrastrand crosslinks (CPD and 1,2-GG) their bypass by high-fidelity DNA polymerases is impossible. Being able to bypass cisplatin crosslinks, XPV enables cells to gain resistance against cisplatin-based chemotherapy.

\subsection{Crystal structure of the yeast XPV (Rad30) in complex with 1,2-GG cisplatin}

Alt et al. (2007) solved the crystal structure of XPV replicating over 1,2-GG containing DNA. This structure provided insights into the molecular mechanism that allows replication of XPV across strongly distorting DNA lesions. 1,2-GG and 1,3-GTG cisplatin adducts are formed in a typical cancer therapy with cisplatin. In the structure, XPV accommodates the full 1,2-GG adduct in its active site where it properly base pairs the 3' G of the 1,2-GG lesion with a dCTP (Fig. 18). For the nucleotidyl transfer, the DNA rotates into an active conformation, supported by hydrogen bonding of the temple base to the dCTP. The bypass of the $3^{\prime}-\mathrm{dG}$ of $1,2-\mathrm{GG}$ is more efficient and accurate than the bypass of the $5^{\prime}$-dG. In the palm domain, Asp30 and Asp155 coordinate the divalent cations in the active site and Glu156 is responsible for the catalysis. Glu39 plays a structural role too, because it maintains the integrity of the fingers domain. Arg73 coordinates the incoming dNTP for the lesion bypass step and stacks on top of the base moiety. Two magnesium ions are coordinated by the catalytically essential residues.

\subsection{Crystal structure of the yeast XPV (Rad30) in complex with the CPD lesion}

Silverstein et al. (2010b) determined the crystal structure of yeast Rad30 in complex with a cis-syn T-T dimer lesion. These authors argue that crystal contacts between the palm and the PAD domain of two neighboring proteins in the crystal lattice influence the binding of the protein to the DNA. The group performed a double-mutation (K140A, S144W) to eliminate these contacts, and indeed crystals were obtained with a different space group. Deeper analysis of the structure shows that the finger domain is a little more closed but the situation in the active site is almost unchanged compared with the yeast structure (Alt et al. 2007). Figure 19 shows the XPV structure with its different domains, the containing T-T dimer and the incoming dATP. Again the large active site accommodates the dinucleotide lesion very similar to what was already shown by Alt et al. for the cisplatin lesion. The 3'T of the dimer interacts with the incoming dATP by Watson-Crick hydrogen bonding. The 5'T of the lesion builds van der Waals contacts with Met74 and Arg73 of the finger domain. The active site residues of the palm domain (Asp30, Asp155 and Glu156) catalyze the nucleotidyl transfer reaction. By mutational analysis and biochemical assays Silverstein et al. could show that the residues Gln55, Arg73 and Met74 interact with the T-T dimer to keep the lesion in the active site. 
(a)
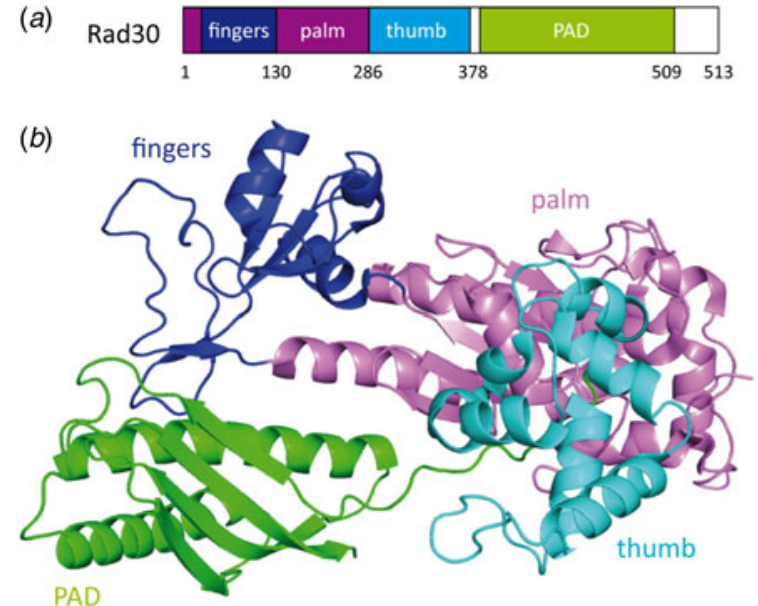

Fig. 17. (a) Structural domains of yeast XPV (Rad30) (Silverstein et al. 2010b). (b) Structure of the catalytic domain of S. cerevisiae XPV showing the four domains (PDB code: 1JIH) (Trincao et al. 2001). The fingers domain is depicted in dark blue, the PAD domain in green, the ThM in cyan and the palm domain in purple.

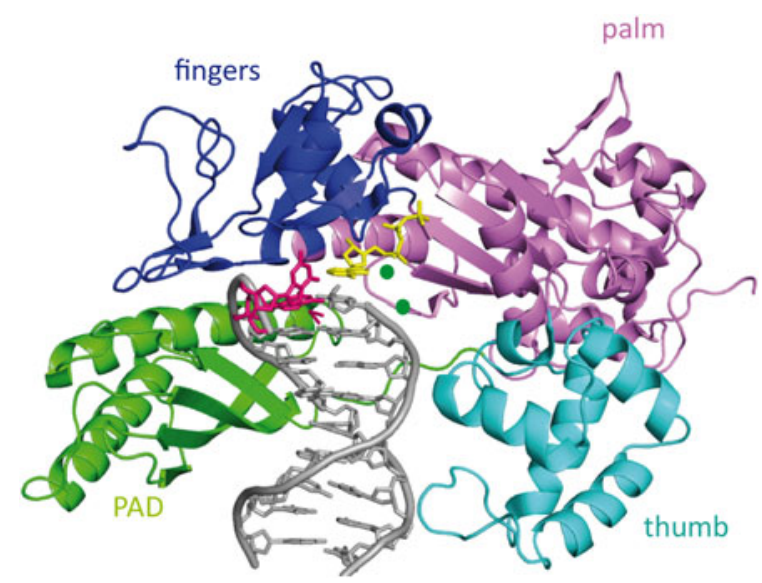

Fig. 18. Crystal structure of Rad30 in complex with 1,2-GG cisplatin adduct (PDB code: 2R8 K) (Alt et al. 2007). Rad30 has right-hand structure containing four domains: palm (violet), thumb (cyan), finger domain (dark blue) and the additional PAD domain (green) which is unique for Y-family polymerases. The cisplatin adduct is depicted in pink, the dCTP in yellow and the two metal ions in green.

\subsection{Crystal structure of the human XPV in complex with the CPD lesion}

Biertumpfel et al. (2010) reported the crystal structure of the catalytic core (residues 1-432) of human polymerase $\eta$ at four consecutive steps during DNA synthesis through cis-syn CPD lesion (Fig. 20b). They could show on a molecular level how human XPV efficiently bypasses the lesion in TLS. Human XPV, similar to its yeast homolog, consists of four domains: palm, PAD (little fingers), thumb and the fingers (Fig. 20a). The active site is situated in the palm domain and the DNA is bound between the thumb and the finger domains. Acting as a molecular splint the polymerase keeps the damaged DNA straight and rigid in its B-form conformation in contrast to the bent and unwound structures of CPD containing DNA with other repair enzymes or alone. The $\beta$-strand in the little finger is nearly parallel to the template strand and hydrogen bonding of the main chain amides to the phosphate supports this conformation. Again, the most prominent feature is the large active site of the protein already reported by Alt et al. (2007), which is able to accommodate two bases of the template strand instead of one. The $3^{\prime}$ thymine of CPD is base paired with the incoming dATP, while the $5^{\prime}$ thymine is turned and moved closer to the finger domain which leads to tighter interactions than the ones observed with undamaged DNA. Furthermore, the two residues Arg61 and Glu38 that are conserved among the XPV homologs create specific hydrogen bonds with the incoming dATP and the CPD lesion. Again, the human XPV shows a more closed finger domain, which contacts the replicating base pair more intensively. Based on all these structures we can therefore assume that the finger domain is quite flexible and that the more closed structure is the conformation the protein assumes in the processive mode. 


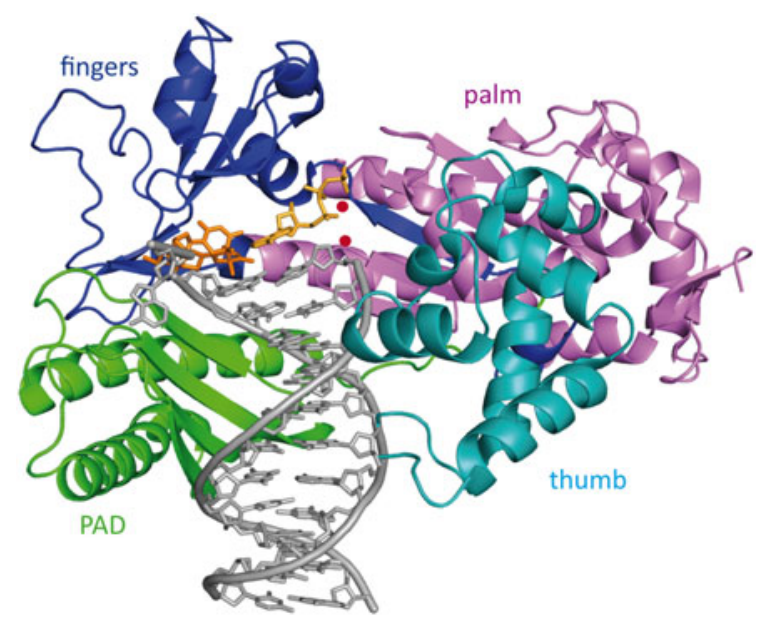

Fig. 19. Structure of Rad30 with a CPD lesion. The cis-syn T-T dimer is depicted in orange and the incoming dATP is shown in yellow (PDB code: 3MFI) (Silverstein et al. 2010b). The four domains are depicted with different colors: fingers (blue), palm (violet), PAD (green) and thumb (light blue). The two $\mathrm{Mg}^{2+}$ ions in the active site are colored in red.

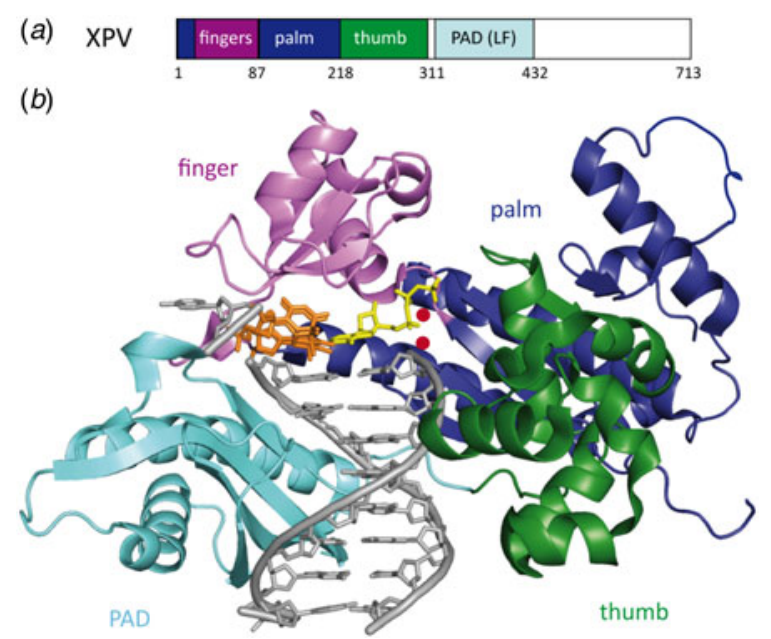

Fig. 20. (a) Schematic representation of human XPV showing the different domains. The finger domain is depicted in purple, the palm domain in dark blue, the ThM in green and PAD domain (little fingers) in cyan. (b) Crystal structure of human XPV in complex with CPD damaged DNA (PDB code: 3MR3) (Biertumpfel et al. 2010). Same color code as in (a). The CPD lesion is shown in orange and the dAMPNPP $\left(2^{\prime}\right.$-deoxy-adenosine-5'-[( $\left.\alpha, \beta\right)$-imido]-triphosphate) is shown in yellow. The two $\mathrm{Mg}^{2+}$ ions of the active site are depicted in red.

Further crystal structures of human and yeast XPV could be resolved with different DNA damages such as 1,3-GTG cisplatin or 8-oxoG (Reissner et al. 2010; Silverstein et al. 2010a). Schorr \& Carell (2010a) crystallized the S. cerevisiae XPV (Rad30) with an AAF-dG lesion and they proposed a model for lesion bypass. In vivo experiments show that Pol $\eta$ indeed replicates through acetylated aromatic amine lesions such as AAF-dG (Bresson \& Fuchs, 2002). In vitro studies revealed that both human and yeast XPV base pair the AAF-dG lesion correctly with dC (Bresson \& Fuchs, 2002; Livneh, 2001; Masutani et al. 2000; Matsuda et al. 2000) and are able to catalyze the extension from the lesion, however, with reduced efficiency (Masutani et al. 2000). In addition, XPV also incorporates a correct dCTP opposite the $N^{2}$-AAF-dG adduct (Yasui et al. 2004). It has also been shown that XPV is responsible for the occurrence of frameshift mutations in response to the presence of aromatic amine lesions during replication (Bresson \& Fuchs, 2002; Cordonnier et al. 1999).

\section{Conclusion}

In this review, we presented the most recent eukaryotic structures of the XP proteins in complex with their DNA substrate. When no co-crystal structures with the DNA substrate were obtained we discussed the models of protein-DNA interaction 
that were proposed. All these structures led to a dramatic increase of our understanding of the role of the individual XP proteins in DNA damage repair and tolerance. The structures allow to determine binding partner regions and to elucidate on a molecular level the interaction between the proteins and their DNA substrates. Now, further studies have to be done in order to better understand the correlation between genetic defects and the role of the various XP proteins in NER and TLS. We also need further human structural information and most importantly structures of the XP proteins in functional complexes with the other involved NER proteins. This would allow deciphering of the protein-protein interactions on the DNA damage site and it may shed light on the correlation to genetic disorders. Understanding the mechanism of NER and TLS in correlation with human genetic disorders unveils the biological basis for oncogenesis and aging. Last but not least, proteomics data are needed to uncover the functional relations of the proteins involved in replication, transcription and repair.

\section{Acknowledgements}

We thank the Deutsche Forschungsgemeinschaft SFB-646, SFB-749 and the excellence cluster CIPS ${ }^{\mathrm{M}}$ for financial support. We also thank Dr. Jochen Kuper, Wolfgang Koelmel, Dr. Dorothea Matschkal, Dr. Iacovos N. Michaelides and Dr. Sabine Schneider for critical reading of the manuscript. We thank Dr. Markus Mueller for helpful advice.

\section{References}

Abdulrahman, W., Iltis, I., Radu, L., Braun, C., Maglott-Roth, A., Giraudon, C., Egly, J. M. \& Poterszman, A. (2013). ARCH domain of $\mathrm{XPD}$, an anchoring platform for CAK that conditions TFIIH DNA repair and transcription activities. Proceedings of the National Academy of Sciences of the United States of America 110, E633-E642.

Aboussekhra, A., Biggerstaff, M., Shivji, M. K., Vilpo, J. A., Moncollin, V., Podust, V. N., Protic, M., Hubscher, U., Egly, J. M. \& Wood, R. D. (1995). Mammalian DNA nucleotide excision repair reconstituted with purified protein components. Cell 80, 859-868.

Alt, A., Lammens, K., Chiocchini, C., Lammens, A., Pieck, J. C., Kuch, D., Hopfner, K. P. \& Carell, T. (2007). Bypass of DNA lesions generated during anticancer treatment with cisplatin by DNA polymerase eta. Science 318, 967-970.

Araki, M., Masutani, C., Takemura, M., Uchida, A., Sugasawa, K., Kondoh, J., Ohkuma, Y. \& Hanaoka, F. (2001). Centrosome protein centrin $2 /$ caltractin 1 is part of the xeroderma pigmentosum group $\mathrm{C}$ complex that initiates global genome nucleotide excision repair. The Journal of Biological Chemistry 276, 18665-18672.

Araujo, S. J., NigG, E. A. \& Wood, R. D. (2001). Strong functional interactions of TFIIH with XPC and XPG in human DNA nucleotide excision repair, without a preassembled repairosome. Molecular and Cellular Biology 21, 2281-2291.

Araujo, S. J., Tirode, F., Coin, F., Pospiech, H., Syvaoja, J. E., Stucki, M., Hubscher, U., Egly, J. M. \& Wood, R. D. (2000). Nucleotide excision repair of DNA with recombinant human proteins: definition of the minimal set of factors, active forms of TFIIH, and modulation by CAK. Genes \& Development 14, 349-359.

Asahina, H., Kuraoka, I., Shirakawa, M., Morita, E. H., Miura, N., Miyamoto, I., Ohtsuka, E., Okada, Y. \& Tanaka, K. (1994). The XPA protein is a zinc metalloprotein with an ability to recognize various kinds of DNA damage. Nature Structural \& Molecular Biology 315, 229-237.

BatTy, D., RapiC'-Otrin, V., Levine, A. S. \& Wood, R. D. (2000a). Stable binding of human XPC complex to irradiated DNA confers strong discrimination for damaged sites. Journal of Molecular Biology 300, 275-290.

BAtTY, D. P. \& Wood, R. D. (2000b). Damage recognition in nucleotide excision repair of DNA. Gene 241, $193-204$.

Bernardes de Jesus, B. M., Bjoras, M., Coin, F. \& Egly, J. M. (2008). Dissection of the molecular defects caused by pathogenic mutations in the DNA repair factor XPC. Molecular and Cellular Biology 28, 7225-7235.

Berneburg, M. \& Lehmann, A. R. (2001). Xeroderma pigmentosum and related disorders: defects in DNA repair and transcription. Advances in Genetics 43, 71-102.

Biertumpfel, C., Zhao, Y., Kondo, Y., Ramon-Maiques, S., Gregory, M., Lee, J. Y., Masutani, C., Lehmann, A. R., Hanaoka, F. \& Yang, W. (2010). Structure and mechanism of human DNA polymerase eta. Nature 465, 1044-1048.

Bootsma, D. \& Hoeijmakers, J. H. (1993). DNA repair. Engagement with transcription. Nature 363, 114-115.

BRESSON, A. \& FuCHS, R. P. (2002). Lesion bypass in yeast cells: Pol eta participates in a multi-DNA polymerase process. The EMBO Journal 21, 3881-3887.

Brookman, K. W., Lamerdin, J. E., Thelen, M. P., Hwang, M., Reardon, J. T., Sancar, A., Zhou, Z. Q., Walter, C. A., Parris, C. N. \& Thompson, L. H. (1996). ERCC4 (XPF) encodes a human nucleotide excision repair protein with eukaryotic recombination homologs. Molecular and Cellular Biology 16, 6553-6562.

Brooks, P. J., Wise, D. S., Berry, D. A., Kosmoski, J. V., Smerdon, M. J., Somers, R. L., Mackie, H., Spoonde, A. Y., Ackerman, E. J., Coleman, K., Tarone, R. E. \& Robbins, J. H. (2000). The oxidative DNA lesion 8,5'-(S)-cyclo-2'-deoxyadenosine is repaired by the nucleotide excision repair pathway and blocks gene expression in mammalian cells. The Journal of Biological Chemistry 275, 22355-22362.

Buchko, G. W., Ni, S., Thrall, B. D. \& Kennedy, M. A. (1998). Structural features of the minimal DNA binding domain (M98-F219) of human nucleotide excision repair protein XPA. Nucleic Acids Research 26, 2779-2788. 
Buchko, G. W., Tung, C. S., McAteer, K., Isern, N. G., Spicer, L. D. \& Kennedy, M. A. (2001). DNA-XPA interactions: a ${ }^{31}$ P NMR and molecular modeling study of dCCAATAACC association with the minimal DNA-binding domain (M98-F219) of the nucleotide excision repair protein XPA. Nucleic Acids Research 29, 2635-2643.

Buechner, C. N., Heil, K., Michels, G., Carell, T., Kisker, C. \& Tessmer, I. (2014). Strand-specific recognition of DNA damages by XPD provides insights into nucleotide excision repair substrate versatility. The Journal of Biological Chemistry 289, 3613-3624.

Burns, J. L., Guzder, S. N., Sung, P., Prakash, S. \& Prakash, L. (1996). An affinity of human replication protein A for ultraviolet-damaged DNA. The Journal of Biological Chemistry 271, 11607-11610.

Buschta-Hedayat, N., Buterin, T., Hess, M. T., Missura, M. \& Naegeli, H. (1999). Recognition of nonhybridizing base pairs during nucleotide excision repair of DNA. Proceedings of the National Academy of Sciences of the United States of America 96, 6090-6095.

Buterin, T., Hess, M. T., Luneva, N., Geacintov, N. E., Amin, S., Kroth, H., Seidel, A. \& Naegeli, H. (2000). Unrepaired Fjord region polycyclic aromatic hydrocarbon-DNA adducts in ras codon 61 mutational hot spots. Cancer Research 60, 1849-1856.

Camenisch, U., Dip, R., Schumacher, S. B., Schuler, B. \& Naegeli, H. (2006). Recognition of helical kinks by xeroderma pigmentosum group A protein triggers DNA excision repair. Nature Structural and Molecular Biology 13, 278-284.

CAmenisch, U. \& NäGeli, H. (2008). XPA gene, its product and biological roles. Advances in Experimental Medicine and Biology 637, 28-38.

Camenisch, U., Trautlein, D., Clement, F., Fei, J., Leitenstorfer, A., Ferrando- May, E. \& Naegeli, H. (2009). Two-stage dynamic DNA quality check by xeroderma pigmentosum group C protein. EMBO Journal 28, 2387-2399.

Chen, X., Velmurugu, Y., Zheng, G., Park, B., Shim, Y., Kim, Y., Liu, L., Van Houten, B., He, C., Ansaria, A. \& Min, J. (2015). Kinetic gating mechanism of DNA damage recognition by Rad4/XPC. Nature Communications 6, 5849.

Chu, G. \& Chang, E. (1988). Xeroderma pigmentosum group E cells lack a nuclear factor that binds to damaged DNA. Science 242, 564-567.

Citterio, E., Van Den Boom, V., Schnitzler, G., Kanaar, R., Bonte, E., Kingston, R. E., Hoeijmakers, J. H. \& Vermeulen, W. (2000). ATP-dependent chromatin remodeling by the Cockayne syndrome B DNA repair-transcription-coupling factor. Molecular and Cellular Biology 20, 7643-7653.

Cleaver, J. E. (2000). Common pathways for ultraviolet skin carcinogenesis in the repair and replication defective groups of xeroderma pigmentosum. Journal of Dermatological Science 23, 1-11.

Cleaver, J. E., Lam, E. T. \& Revet, I. (2009). Disorders of nucleotide excision repair: the genetic and molecular basis of heterogeneity. Nature Reviews Genetics 10, 756-768.

Cleaver, J. E. \& States, J. C. (1997). The DNA damage-recognition problem in human and other eukaryotic cells: the XPA damage binding protein. Biochemical Journal 328, 1-12.

Coin, F., Marinoni, J. C., Rodolfo, C., Fribourg, S., Pedrini, A. M. \& Egly, J. M. (1998). Mutations in the XPD helicase gene result in XP and TTD phenotypes, preventing interaction between XPD and the p44 subunit of TFIIH. Nature Genetics 20, 184-188.

Coin, F., Oкsenych, V. \& Egly, J. M. (2007). Distinct roles for the XPB/p52 and XPD/p44 subcomplexes of TFIIH in damaged DNA opening during nucleotide excision repair. Molecular Cell 26, 245-256.

Coin, F., Oksenych, V., Mocquet, V., Groh, S., Blattner, C. \& Egly, J. M. (2008). Nucleotide excision repair driven by the dissociation of CAK from TFIIH. Molecular Cell 31, 9-20.

Constantinou, A., Gunz, D., Evans, E., Lalle, P., Bates, P. A., Wood, R. D. \& Clarkson, S. G. (1999). Conserved residues of human XPG protein important for nuclease activity and function in nucleotide excision repair. The Journal of Biological Chemistry 274, 5637-5648.

Cordonnier, A. M., Lehmann, A.R. \& FuChs, R. P. (1999). Impaired translesion synthesis in xeroderma pigmentosum variant extracts. Molecular and Cellular Biology 19, 2206-2211.

Das, D., Folkers, G. E., van Dijk, M., Jaspers, N. G., Hoeijmakers, J. H., Kaptein, R. \& Boelens, R. (2012). The structure of the XPF-ssDNA complex underscores the distinct roles of the XPF and ERCC1 helix- hairpin-helix domains in ss/ds DNA recognition. Structure 20, 667-675.

Das, D., Tripsianes, K., Jaspers, N. G., Hoeijmakers, J. H., Kaptein, R., Boelens, R. \& Folkers, G. E. (2008). The HhH domain of the human DNA repair protein XPF forms stable homodimers. Proteins 70, 1551-1563.

de Laat, W. L., Appeldoorn, E., Sugasawa, K., Weterings, E., Jaspers, N. G. J. \& Hoeijmakers, J. H. J. (1998). DNA-binding polarity of human replication protein A positions nucleases in nucleotide excision repair. Genes \& Development 12, 2598-2609.

de LaAt, W. L., Jaspers, N. G. \& Hoeijmakers, J. H. (1999). Molecular mechanism of nucleotide excision repair. Genes \& Development 13, $768-785$.

De Weerd-Kastelein, E. A., Keizzer, W. \& Bootsma, D. (1972). Genetic heterogeneity of xeroderma pigmentosum demonstrated by somatic cell hybridization. Nature: New Biology 238, 80-83.

Demple, B. \& Harrison, L. (1994). Repair of oxidative damage to DNA: enzymology and biology. Annual Review of Biochemistry 63, 915-948.

Donahue, B. A., Yin, S., Taylor, J. S., Reines, D. \& Hanawalt, P.C. (1994). Transcript cleavage by RNA polymerase II arrested by a cyclobutane pyrimidine dimer in the DNA template. Proceedings of the National Academy of Sciences of the United States of America 91, 8502-8506.

Dubaele, S., Proietti De Santis, L., Bienstock, R. J., Keriel, A., Stefanini, M., Van Houten, B. \& Egly, J. M. (2003). Basal transcription defect discriminates between xeroderma pigmentosum and trichothiodystrophy in XPD patients. Molecular Cell 11, 1635-1646.

Dunand-Sauthier, I., Hohl, M., Thorel, F., Jaquier-Gubler, P., Clarkson, S. G. \& Scharer, O. D. (2005). The spacer region of XPG mediates recruitment to nucleotide excision repair complexes and determines substrate specificity. The Journal of Biological Chemistry 280, 70307037.

Edengerg, H. \& Hanawalt, P. (1972). Size of repair patches in the DNA of ultraviolet-irradiated HeLa cells. Biochimica et Biophysica Acta 272 361-372. 
El-Mahdy, M. A., Zhu, Q., Wang, Q. E., Wani, G., PraEtorius-IbBa, M., Wani, A. A. (2006). Cullin 4A-mediated proteolysis of DDB2 protein at DNA damage sites regulates in vivo lesion recognition by XPC. Journal of Biological Chemistry 281, 13404-13411.

Evans, E., Fellows, J., Coffer, A. \& Wood, R. D. (1997a). Open complex formation around a lesion during nucleotide excision repair provides a structure for cleavage by human XPG protein. The EMBO Journal 16, 625-638.

Evans, E., Moggs, J. G., Hwang, J. R., Egly, J. M. \& Wood, R. D. (1997b). Mechanism of open complex and dual incision formation by human nucleotide excision repair factors. The EMBO Journal 16, 6559-6573.

Fagbemi, A. F., Orelli, B. \& Scharer, O. D. (2011). Regulation of endonuclease activity in human nucleotide excision repair. DNA Repair 10, $722-729$.

Fan, L., Arvai, A. S., Cooper, P. K., Iwai, S., Hanaoka, F. \& Tainer, J. A. (2006). Conserved XPB core structure and motifs for DNA unwinding: implications for pathway selection of transcription or excision repair. Molecular Cell 22, 27-37.

Fan, L., Fuss, J. O., Cheng, Q. J., Arvai, A. S., Hammel, M., Roberts, V. A., Cooper, P. K. \& Tainer, J. A. (2008). XPD helicase structures and activities: insights into the cancer and aging phenotypes from XPD mutations. Cell 133, 789-800.

Feltes, B. C. \& Bonatto, D. (2015). Overview of xeroderma pigmentosum proteins architecture, mutations and post-translational modifications. Mutation Research/Reviews in Mutation Research 763, 306-320.

Fischer, E. S., Scrima, A., Bohm, K., Matsumoto, S., Lingaraju, G. M., Faty, M., Yasuda, T., Cavadini, S., Wakasugi, M., Hanaoka, F., Iwai, S., Gut, H., Sugasawa, K. \& Thoma, N. H. (2011). The molecular basis of CRL4DDB2/CSA ubiquitin ligase architecture, targeting, and activation. Cell 147, 1024-1039.

FITCH, M. E., NAKAJIMA, S., YAsUI, A. \& Ford, J. M. (2003). In vivo recruitment of XPC to UV-induced cyclobutane pyrimidine dimers by the DDB2 gene product. The Journal of Biological Chemistry 278, 46906-46910.

FriedBerg, E. C. (1995). DNA Repair and Mutagenesis. Waschington, D.C: ASM Press.

FriedberG, E. C. (2001). How nucleotide excision repair protects against cancer. Nature Review Cancer 1, 22-33.

FriedberG, E. C. (2005). Suffering in silence: the tolerance of DNA damage. Nature Reviews Molecular Cell Biology 6, $943-953$.

Fujiwara, Y., Masutani, C., Mizukoshi, T., Kondo, J., Hanaoka, F. \& Iwai, S. (1999). Characterization of DNA recognition by the human UV-damaged DNA-binding protein. The Journal of Biological Chemistry 274, 20027-20033.

Fuss, J. O. \& TAINER, J. A. (2011). XPB and XPD helicases in TFIIH orchestrate DNA duplex opening and damage verification to coordinate repair with transcription and cell cycle via CAK kinase. DNA Repair 10, 697-713.

Geacintov, N. E., Broyde, S., Buterin, T., Naegeli, H., Wu, M., Yan, S. \& Patel, D. J. (2002). Thermodynamic and structural factors in the removal of bulky DNA adducts by the nucleotide excision repair machinery. Biopolymers 65, 202-210.

Gillet, L. C., Alzeer, J. \& Scharer, O. D. (2005). Site-specific incorporation of N-(deoxyguanosin-8-yl)-2-acetylaminofluorene (dG-AAF) into oligonucleotides using modified 'ultra-mild' DNA synthesis. Nucleic Acids Research 33, 1961-1969.

Gillet, L. C. \& Scharer, O. D. (2006). Molecular mechanisms of mammalian global genome nucleotide excision repair. Chemical Reviews 106, $253-276$.

Groisman, R., Polanowska, J., Kuraoka, I., Sawada, J., Saijo, M., Drapkin, R., Kisselev, A. F., Tanaka, K., Nakatani, Y. (2003). The ubiquitin ligase activity in the DDB2 and CSA complexes is differentially regulated by the COP9 signalosome in response to DNA damage. Cell 113, $357-367$.

Gunz, D., Hess, M. T. \& NAegel, H. (1996). Recognition of DNA adducts by human nucleotide excision repair. Evidence for a thermodynamic probing mechanism. The Journal of Biological Chemistry 271, 25089-25098.

Guzder, S. N., Sung, P., Bailly, V., Prakash, L. \& Prakash, S. (1994). RAD25 is a DNA helicase required for DNA repair and RNA polymerase II transcription. Nature 369, 578-581.

Hanawalt, P. C. \& SpivaK, G. (2008). Transcription-coupled DNA repair: two decades of progress and surprises. Nature Reviews Molecular Cell Biology 9, 958-970.

Haracska, L., Yu, S. L., Johnson, R. E., Prakash, L. \& Prakash, S. (2000). Efficient and accurate replication in the presence of 7,8-dihydro-8-oxoguanine by DNA polymerase eta. Nature Genetics $25,458-461$.

He, Z., Henricksen, L. A., Wold, M. S. \& Ingles, C. J. (1995). RPA involvement in the damage-recognition and incision steps of nucleotide excision repair. Nature 374, 566-569.

Hebra, F. \& Kaposi, M. (1874). On diseases of the skin including the exanthemata. The New Sydenham Society 61, 252-258.

Hess, M. T., Gunz, D., Luneva, N., Geacintov, N. E. \& Naegeli, H. (1997a). Base pair conformation-dependent excision of benzo[a]pyrene diol epoxide-guanine adducts by human nucleotide excision repair enzymes. Molecular and Cellular Biology 17, 7069-7076.

Hess, M. T., Gunz, D. \& Naegeli, H. (1996a). A repair competition assay to assess recognition by human nucleotide excision repair. Nucleic Acids Research 24, 824-828.

Hess, M. T., Schwitter, U., Petretta, M., Giese, B. \& Naegeli, H. (1996b). Site-specific DNA substrates for human excision repair: comparison between deoxyribose and base adducts. Chemical Biology 3, 121-128.

Hess, M. T., Schwitter, U., Petretta, M., Giese, B. \& Nafgeli, H. (1997b). Bipartite substrate discrimination by human nucleotide excision repair. Proceedings of the National Academy of Sciences of the United States of America 94, 6664-6669.

Hess, N. J., Buchro, G. W., Conradson, S. D., Espinosa, F. J., Ni, S., Thrall, B. D. \& Kennedy, M. A. (1998). Human nucleotide excision repair protein XPA: extended X-ray absorption fine-structure evidence for a metal-binding domain. Protein Science 7, 1970-1975.

Hey, T., Lipps, G., Sugasawa, K., Iwai, S., Hanaoka, F. \& Krauss, G. (2002). The XPC-HR23B complex displays high affinity and specificity for damaged DNA in a true-equilibrium fluorescence assay. Biochemistry 41, 6583-6587.

Hilario, E., Li, Y., Nobumori, Y., Liu, X. \& Fan, L. (2013). Structure of the C-terminal half of human XPB helicase and the impact of the disease-causing mutation XP11BE. Acta Crystallographica D: Biological Crystallography 69, 237-246. 
Hotijmakers, J. H. (2001). Genome maintenance mechanisms for preventing cancer. Nature 411, 366-374.

Hohl, M., Dunand-Sauthier, I., Staresincic, L., Jaquier-Gubler, P., Thorel, F., Modesti, M., Clarkson, S. G. \& Scharer, O. D. (2007). Domain swapping between FEN-1 and XPG defines regions in XPG that mediate nucleotide excision repair activity and substrate specificity. Nucleic Acids Research 35, 3053-3063.

Hohl, M., Thorel, F., Clarkson, S. G. \& Scharer, O. D. (2003). Structural determinants for substrate binding and catalysis by the structurespecific endonuclease XPG. The Journal of Biological Chemistry 278, 19500-19508.

Hoogstraten, D., Nigg, A. L., Heath, H., Mullenders, L. H., van Driel, R., Hoeijmakers, J. H., Vermeulen, W. \& Houtsmuller, A. B. (2002). Rapid switching of TFIIH between RNA polymerase I and II transcription and DNA repair in vivo. Molecular Cell 10, 1163-1174.

Hosfield, D. J., Mol, C. D., Shen, B. \& TAINer, J. A. (1998). Structure of the DNA repair and replication endonuclease and exonuclease FEN-1: coupling DNA and PCNA binding to FEN-1 activity. Cell 95, 135-146.

Houle, J. F. \& Friedberg, E. C. (1999). The Drosophila ortholog of the human XPG gene. Gene 234, 353-360.

Houtsmuller, A. B., Rademakers, S., Nigg, A. L., Hoogstraten, D., Hoeijmakers, J. H. \& Vermeulen, W. (1999). Action of DNA repair endonuclease ERCC1/XPF in living cells. Science 284, 958-961.

Huang, J. C., Hsu, D. S., Kazantsev, A. \& Sancar, A. (1994). Substrate spectrum of human excinuclease: repair of abasic sites, methylated bases, mismatches, and bulky adducts. Proceedings of the National Academy of Sciences of the United States of America $\mathbf{9 1}$, $12213-12217$.

Hwang, B. J., Ford, J. M., Hanawalt, P. C. \& Chu, G. (1999). Expression of the p48 xeroderma pigmentosum gene is p53-dependent and is involved in global genomic repair. Proceedings of the National Academy of Sciences of the United States of America 96, 424-428.

Hwang, B. J., Toering, S., Francke, U. \& Chu, G. (1998a). p48 Activates a UV-damaged-DNA binding factor and is defective in xeroderma pigmentosum group E cells that lack binding activity. Molecular and Cellular Biology 18, 4391-4399.

Hwang, K. Y., BAeK, K., Kiм, H. Y. \& Cho, Y. (1998b). The crystal structure of flap endonuclease-1 from Methanococcus jannaschii. Nature Structural \& Molecular Biology 5, 707-713.

Ikegami, T., Kuraoka, I., Saijo, M., Kodo, N., Kyogoku, Y., Morikawa, K., Tanaka, K. \& Shirakawa, M. (1998). Solution structure of the DNAand RPA-binding domain of the human repair factor XPA. Nature Structural \& Molecular Biology 5, 701-706.

IsAacs, R. J. \& SPIELMANn, H. P. (2004). A model for initial DNA lesion recognition by NER and MMR based on local conformational flexibility. DNA Repair 3, 455-464.

Iyer, N., Reagan, M. S., Wu, K. J., Canagarajah, B. \& Friedberg, E. C. (1996). Interactions involving the human RNA polymerase II transcription/nucleotide excision repair complex TFIIH, the nucleotide excision repair protein XPG, and Cockayne syndrome group B (CSB) protein. Biochemistry 35, 2157-2167.

Johnson, R. E., Washington, M. T., Haracska, L., Prakash, S. \& Prakash, L. (2000). Eukaryotic polymerases iota and zeta act sequentially to bypass DNA lesions. Nature 406, 1015-1019.

Jones, C. J. \& Wood, R. D. (1993). Preferential binding of the xeroderma pigmentosum group A complementing protein to damaged DNA. Biochemistry 32, 12096-12104.

Kamiuchi, S., Saijo, M., Citterio, E., De Jager, M., Hoeijmakers, J. H. \& Tanaka, K. (2002). Translocation of Cockayne syndrome group A protein to the nuclear matrix: possible relevance to transcription-coupled DNA repair. Proceedings of the National Academy of Sciences of the United States of America 99, 201-206.

Katsumi, S., Kobayashi, N., Imoto, K., Nakagawa, A., Yamashina, Y., Muramatsu, T., Shirai, T., Miyagawa, S., Sugiura, S., Hanaoka, F., Matsunaga, T., Nikaido, O. \& Mori, T. (2001). In situ visualization of ultraviolet-light-induced DNA damage repair in locally irradiated human fibroblasts. Journal of Investigative Dermatology 117, 1156-1161.

KeENeY, S., ChANG, G. J. \& LinN, S. (1993). Characterization of a human DNA damage binding protein implicated in xeroderma pigmentosum E. The Journal of Biological Chemistry 268, 21293-21300.

Kim, T. K., Ebright, R. H. \& Reinberg, D. (2000). Mechanism of ATP-dependent promoter melting by transcription factor IIH. Science 288, $1418-1422$.

Kobayashi, T., Takeuchi, S., Saijo, M., Nakatsu, Y., Morioka, H., Otsuka, E., Wakasugi, M., Nikaido, O. \& Tanaka, K. (1998). Mutational analysis of a function of xeroderma pigmentosum group A (XPA) protein in strand-specific DNA repair. Nucleic Acids Research 26, $4662-4668$.

Koch, S. C., Kuper, J., Gasteiger, K. L., Simon, N., Strasser, R., Eisen, D., Geiger, S., Schneider, S., Kisker, C. \& Carell, T. (2015). Structural insights into the recognition of cisplatin and AAF-dG lesion by Rad14 (XPA). Proceedings of the National Academy of Sciences of the United States of America 112, 8272-8277.

Kondratick, C. M., Washington, M. T., Prakash, S. \& Prakash, L. (2001). Acidic residues critical for the activity and biological function of yeast DNA polymerase eta. Molecular and Cellular Biology 21, 2018-2025.

Kuper, J., Braun, C., Elias, A., Michels, G., Sauer, F., Schmitt, D. R., Poterszman, A., Egly, J. M. \& Kisker, C. (2014). In TFIIH, XPD helicase is exclusively devoted to DNA repair. PLoS Biology 12, e1001954.

Kuper, J., Wolski, S. C., Michels, G. \& Kisker, C. (2012). Functional and structural studies of the nucleotide excision repair helicase XPD suggest a polarity for DNA translocation. The EMBO Journal 31, 494-502.

Kuraoka, I., Morita, E. H., Saijo, M., Matsuda, T., Morikawa, K., Shirakawa, M. \& Tanaka, K. (1996). Identification of a damaged-DNA binding domain of the XPA protein. Mutation Research 362, 87-95.

Kusumoto, R., Masutani, C., Sugasawa, K., Imai, S., Araki, M., Uchida, A., Mizukoshi, T. \& Hanaoka, F. (2001). Diversity of the damage recognition step in the global genomic nucleotide excision repair in vitro. Mutation Research 485, 219-227.

Lehmann, A. R. (2001). The xeroderma pigmentosum group D (XPD) gene: one gene, two functions, three diseases. Genes \& Development 15, $15-23$. 
Lehmann, A. R. (2003). DNA repair-deficient diseases, xeroderma pigmentosum, Cockayne syndrome and trichothiodystrophy. Biochimie 85, 1101-1111.

Lehmann, A. R. (2008). XPD structure reveals its secrets. DNA Repair 7, 1912-1915.

Lehmann, A. R., Kirk-Bell, S., Arlett, C. F., Paterson, M. C., Lohman, P. H., de Weerd-Kastelein, E. A. \& Bootsma, D. (1975). Xeroderma pigmentosum cells with normal levels of excision repair have a defect in DNA synthesis after UV-irradiation. Proceedings of the National Academy of Sciences of the United States of America 72, 219-223.

Li, L., Elledge, S. J., Peterson, C. A., BAles, E. S. \& Legerski, R. J. (1994). Specific association between the human DNA repair proteins XPA and ERCC1. Proceedings of the National Academy of Sciences of the United States of America 91, 5012-5016.

Li, C., Golebiowski, F. M., Onishi, Y., Samara, N. L., Sugasawa, K. \& Yang, W. (2015). Tripartite DNA lesion recognition and verification by XPC, TFIIH, and XPA in nucleotide excision repair. Molecular Cell 59, 1025-1034.

Li, L., Lu, X., Peterson, C. A. \& Legerski, R. J. (1995a). An interaction between the DNA repair factor XPA and replication protein A appears essential for nucleotide excision repair. Molecular and Cellular Biology 15, 5396-5402.

Li, L., Peterson, C. A., Lu, X. \& Legerski, R. J. (1995b). Mutations in XPA that prevent association with ERCC1 are defective in nucleotide excision repair. Molecular and Cellular Biology 15, 1993-1998.

LIEBER, M. R. (1997). The FEN-1 family of structure-specific nucleases in eukaryotic DNA replication, recombination and repair. BioEssays: News and Reviews in Molecular, Cellular and Developmental Biology 19, 233-240.

Liu, H., Rudolf, J., Johnson, K. A., McMahon, S. A., Oke, M., Carter, L., McRobbie, A. M., Brown, S. E., Naismith, J. H. \& White, M. F. (2008). Structure of the DNA repair helicase XPD. Cell 133, 801-812.

LiU, Y., YANG, Z., UtZAT, C., WANG, G., BASU, A. K. \& Zou, Y. (2005). Cooperative interaction of human XPA stabilizes and enhances specific binding of XPA to DNA damage. Biochemistry 44, 7361-7368.

Livneh, Z. (2001). DNA damage control by novel DNA polymerases: translesion replication and mutagenesis. The Journal of Biological Chemistry 276, 25639-25642.

Luijsterburg, M. S., Goedhart, J., Moser, J., Kool, H., Geverts, B., Houtsmuller, A. B., Mullenders, L. H., Vermeulen, W. \& Van Driel, R. (2007). Dynamic in vivo interaction of DDB2 E3 ubiquitin ligase with UV-damaged DNA is independent of damage-recognition protein XPC. Journal of Cell Science 120, 2706-2716.

Luijsterburg, M. S., von Bornstaedt, G., Gourdin, A. M., Politi, A.Z., Mone, M. J., Warmerdam, D. O., Goedhart, J., Vermeulen, W., van DrIel, R. \& Hofer, T. (2010). Stochastic and reversible assembly of a multiprotein DNA repair complex ensures accurate target site recognition and efficient repair. The Journal of Cell Biology 189, 445-463.

LukIN, M. \& de Los SANTos, C. (2006). NMR structures of damaged DNA. Chemical Reviews 106, 607-686.

Maillard, O., Solyom, S. \& Naegeli, H. (2007). An aromatic sensor with aversion to damaged strands confers versatility to DNA repair. PLoS Biology 5(4), e79.

Maltseva, E. A., Rechrunova, N. I., Gillet, L. C., Petruseva, I. O., Scharer, O. D. \& Lavrik, O. I. (2007). Crosslinking of the NER damage recognition proteins XPC-HR23B, XPA and RPA to photoreactive probes that mimic DNA damages. Biochimica et Biophysica Acta 1770, 781-789.

Masutani, C., Araki, M., Yamada, A., Kusumoto, R., Nogimori, T., Maekawa, T., Iwai, S. \& Hanaoka, F. (1999a). Xeroderma pigmentosum variant (XP-V) correcting protein from HeLa cells has a thymine dimer bypass DNA polymerase activity. The EMBO Journal 18, $3491-3501$.

Masutani, C., Kusumoto, R., Iwai, S. \& HanaOKa, F. (2000). Mechanisms of accurate translesion synthesis by human DNA polymerase eta. The EMBO Journal 19, 3100-3109.

Masutani, C., Kusumoto, R., Yamada, A., Dohmae, N., Yokol, M., Yuasa, M., Araki, M., Iwai, S., Takio, K. \& Hanaoka, F. (1999b). The XPV (xeroderma pigmentosum variant) gene encodes human DNA polymerase eta. Nature 399, 700-704.

Mathieu, N., KaczmareK, N. \& NAegeli, H. (2010). Strand- and site-specific DNA lesion demarcation by the xeroderma pigmentosum group D helicase. Proceedings of the National Academy of Sciences of the United States of America 107, 17545-17550.

Mathieu, N., Kaczmarek, N., Ruthemann, P., Luch, A. \& Naegeli, H. (2013). DNA quality control by a lesion sensor pocket of the xeroderma pigmentosum group D helicase subunit of TFIIH. Current Biology 23, 204-212.

Matsuda, T., Bebenek, K., Masutani, C., Hanaoka, F. \& Kunkel, T. A. (2000). Low fidelity DNA synthesis by human DNA polymerase-eta. Nature 404, 1011-1013.

Mellon, I., SpivaK, G. \& Hanawalt, P. C. (1987). Selective removal of transcription-blocking DNA damage from the transcribed strand of the mammalian DHFR gene. Cell 51, 241-249.

Mietus, M., NowaK, E., Jaciuk, M., Kustosz, P., Studnicka, J. \& Nowotny, M. (2014). Crystal structure of the catalytic core of Rad2: insights into the mechanism of substrate binding. Nucleic Acids Research 42, 10762-10775.

Min, J. H. \& Pavletich, N. P. (2007). Recognition of DNA damage by the Rad4 nucleotide excision repair protein. Nature 449, 570-575.

Missura, M., Buterin, T., Hindges, R., Hubscher, U., Kasparkova, J., Brabec, V. \& Naegeli, H. (2001). Double-check probing of DNA bending and unwinding by XPA-RPA: an architectural function in DNA repair. The EMBO Journal 20, 3554-3564.

Mitchell, D. L. \& Nairn, R. S. (1989). The biology of the (6-4) photoproduct. Photochemistry and Photobiology 49, 805-819.

Miyamoto, I., MiUra, N., Niwa, H., Miyazaki, J. \& Tanaka, K. (1992). Mutational analysis of the structure and function of the xeroderma pigmentosum group A complementing protein. Identification of essential domains for nuclear localization and DNA excision repair. The Journal of Biological Chemistry 267, 12182-12187.

Moggs, J. G., Szymkowski, D. E., Yamada, M., Karran, P. \& Wood, R. D. (1997). Differential human nucleotide excision repair of paired and mispaired cisplatin-DNA adducts. Nucleic Acids Research 25, 480-491. 
Moggs, J. G., Yarema, K. J., Essigmann, J.M. \& Wood, R.D. (1996). Analysis of incision sites produced by human cell extracts and purified proteins during nucleotide excision repair of a 1,3-intrastrand $\mathrm{d}(\mathrm{GpTpG})$-cisplatin adduct. The Journal of Biological Chemistry 271, 7177-7186.

Mone, M. J., Volker, M., Nikaido, O., Mullenders, L. H., van Zeeland, A. A., Verschure, P. J., Manders, E. M. \& van Driel, R. (2001). Local UV-induced DNA damage in cell nuclei results in local transcription inhibition. EMBO Reports 2, 1013-1017.

Morikawa, K. \& Shirakawa, M. (2000). Three-dimensional structural views of damaged-DNA recognition: T4 endonuclease V, E. coli Vsr protein, and human nucleotide excision repair factor XPA. Mutation Research 460, 257-275.

Morita, E. H., Ohкubo, T., Kuraoka, I., Shirakawa, M., Tanaka, K. \& Morikawa, K. (1996). Implications of the zinc-finger motif found in the DNA-binding domain of the human XPA protein. Genes to Cells 1, 437-442.

Moser, J., Kool, H., Giakzidis, J., Caldecott, K., Mullenders, L. \& Fousteri, M. I. (2001). Sealing of Chromosomal DNA Nicks during Nucleotide Excision Repair Requires XRCC1 and DNA Ligase III $\alpha$ in a cell-cycle-specific manner. Molecular Cells 27, 311-323.

Moser, J., Kool, H., Giakzidis, I., Caldecott, K., Mullenders, L. H. \& Fousteri, M. I. (2007). Sealing of chromosomal DNA nicks during nucleotide excision repair requires XRCC1 and DNA ligase III alpha in a cell-cycle-specific manner. Molecular Cell 27(2), 311-323.

Mu, D., Bertrand-Burggraf, E., Huang, J. C., Fuchs, R. P., Sancar, A. \& Fuchs, B. P. (1994). Human and E. coli excinucleases are affected differently by the sequence context of acetylaminofluorene-guanine adduct. Nucleic Acids Research 22, 4869-4871.

Mu, D., Park, C. H., Matsunaga, T., Hsu, D. S., Reardon, J. T. \& Sancar, A. (1995). H reconstitution of human DNA repair excision nuclease in a highly defined system. Journal of Biological Chemistry 270, 2415-2418.

Naegeli, H., Bardwell, L. \& Friedberg, E. C. (1992). The DNA helicase and adenosine triphosphatase activities of yeast Rad3 protein are inhibited by DNA damage. A potential mechanism for damage-specific recognition. The Journal of Biological Chemistry 267, 392-398.

Naegeli, H., Modrich, P. \& Friedberg, E. C. (1993). The DNA helicase activities of Rad3 protein of Saccharomyces cerevisiae and helicase II of Escherichia coli are differentially inhibited by covalent and noncovalent DNA modifications. The Journal of Biological Chemistry 268, 10386-10392.

Naegeli, H. \& Sugasawa, K. (2011). The xeroderma pigmentosum pathway: decision tree analysis of DNA quality. DNA Repair 10, 673-683.

Newman, M., Murray-Rust, J., Lally, J., Rudolf, J., Fadden, A., Knowles, P. P., White, M. F. \& McDonald, N. Q. (2005). Structure of an XPF endonuclease with and without DNA suggests a model for substrate recognition. The EMBO Journal 24, 895-905.

Nichols, A. F., ONG, P. \& LinN, S. (1996). Mutations specific to the xeroderma pigmentosum group E Ddb-phenotype. The Journal of Biological Chemistry 271, 24317-24320.

Nishino, T., Komori, K., Ishino, Y. \& MorikaWA, K. (2003). X-ray and biochemical anatomy of an archaeal XPF/Rad1/Mus81 family nuclease: similarity between its endonuclease domain and restriction enzymes. Structure 11, 445-457.

Nocentini, S., Coin, F., SAIJO, M., TANAKA, K. \& EgLY, J. M. (1997). DNA damage recognition by XPA protein promotes efficient recruitment of transcription factor II H. The Journal of Biological Chemistry 272, 22991-22994.

O’Donovan, A., Davies, A. A., Moggs, J. G., West, S. C. \& Wood, R. D. (1994a). XPG endonuclease makes the 3' incision in human DNA nucleotide excision repair. Nature 371, 432-435.

O’Donovan, A., Scherly, D., Clarkson, S. G. \& Wood, R. D. (1994b). Isolation of active recombinant XPG protein, a human DNA repair endonuclease. The Journal of Biological Chemistry 269, 15965-15968.

Ogi, T., Limsirichaikul, S., Overmeer, R. M., Volker, M., Takenaka, K., Cloney, R., Nakazawa, Y., Niimi, A., Miki, Y., Jaspers, N. G., Mullenders, L. H., Yamashita, S., Fousteri, M. I. \& Lehmann, A. R. (2010). Three DNA polymerases, recruited by different mechanisms, carry out NER repair synthesis in human cells. Molecular Cell 37(5), 714-727.

Ohmori, H., Friedberg, E. C., Fuchs, R. P., Goodman, M. F., Hanaoka, F., Hinkle, D., Kunkel, T. A., Lawrence, C. W., Livneh, Z., Nohmi, T., Prakash, L., Prakash, S., Todo, T., Walker, G. C., Wang, Z. \& Woodgate, R. (2001). The Y-family of DNA polymerases. Molecular Cell 8, $7-8$.

Oksenych, V., Bernardes de Jesus, B., Zhovmer, A., Egly, J. M. \& Coin, F. (2009). Molecular insights into the recruitment of TFIIH to sites of DNA damage. The EMBO Journal 28, 2971-2980.

Orans, J., McSweeney, E. A., Iyer, R. R., Hast, M. A., Hellinga, H. W., Modrich, P. \& Beese, L. S. (2011). Structures of human exonuclease 1 DNA complexes suggest a unified mechanism for nuclease family. Cell 145, 212-223.

Park, C. H., Bessho, T., Matsunaga, T. \& Sancar, A. (1995a). Purification and characterization of the XPF-ERCC1 complex of human DNA repair excision nuclease. The Journal of Biological Chemistry 270, 22657-22660.

PARK, C. H., Mu, D., ReARdon, J. T. \& SANCAR, A. (1995b). The general transcription-repair factor TFIIH is recruited to the excision repair complex by the XPA protein independent of the TFIIE transcription factor. The Journal of Biological Chemistry 270, 4896-4902.

PARK, C. H. \& SANCAR, A. (1994). Formation of a ternary complex by human XPA, ERCC1, and ERCC4 (XPF) excision repair proteins. Proceedings of the National Academy of Sciences of the United States of America 91, 5017-5021.

Pugh, R. A., WU, C. G. \& SpIES, M. (2012). Regulation of translocation polarity by helicase domain 1 in SF2B helicases. The EMBO Journal 31, 503-514.

Rademakers, S., Volker, M., Hoogstraten, D., Nigg, A. L., Mone, M. J., Van Zeeland, A. A., Hoeijmakers, J. H., Houtsmuller, A. B. \& Vermeulen, W. (2003). Xeroderma pigmentosum group A protein loads as a separate factor onto DNA lesions. Molecular and Cellular Biology 23, 5755-5767.

RAJSKI, S. R., JACKSON, B. A. \& BARTON, J. K. (2000). DNA repair: models for damage and mismatch recognition. Mutation Research 447, 49-72. 
Raoul, S., BARDET, M. \& CADET, J. (1995). Gamma irradiation of 2'-deoxyadenosine in oxygen-free aqueous solutions: identification and conformational features of formamidopyrimidine nucleoside derivatives. Chemical Research in Toxicology 8, 924-933.

Read, C. M., Cary, P. D., Crane-Robinson, C., Driscoll, P. C. \& Norman, D. G. (1993). Solution structure of a DNA-binding domain from HMG1. Nucleic Acids Research 21, 3427-3436.

Reardon, J. T., Nichols, A. F., Keeney, S., Smith, C. A., Taylor, J. S., Linn, S. \& Sancar, A. (1993). Comparative analysis of binding of human damaged DNA-binding protein (XPE) and Escherichia coli damage recognition protein (UvrA) to the major ultraviolet photoproducts: T[c, $\mathrm{s}] \mathrm{T}, \mathrm{T}[\mathrm{t}, \mathrm{s}] \mathrm{T}, \mathrm{T}[6-4] \mathrm{T}$, and T[Dewar]T. The Journal of Biological Chemistry 268, 21301-21308.

Reardon, J. T. \& Sancar, A. (2002). Molecular anatomy of the human excision nuclease assembled at sites of DNA damage. Molecular and Cellular Biology 22, 5938-5945.

REARdon, J. T. \& SANCAR, A. (2003). Recognition and repair of the cyclobutane thymine dimer, a major cause of skin cancers, by the human excision nuclease. Genes \& Development 17, 2539-2551.

Reardon, J. T. \& Sancar, A. (2005). Nucleotide excision repair. Progress in Nucleic Acid Research and Molecular Biology 79, $183-235$.

Reissner, T., Schneider, S., Schorr, S. \& CARell, T. (2010). Crystal structure of a cisplatin-(1,3-GTG) cross-link within DNA polymerase eta. Angewandte Chemie International Edition 49, 3077-3080.

Riedl, T., Hanaoka, F. \& Egly, J. M. (2003). The comings and goings of nucleotide excision repair factors on damaged DNA. The EMBO Journal 22, 5293-5303.

Robins, P., Jones, C. J., Biggerstaff, M., Lindahl, T. \& Wood, R. D. (1991). Complementation of DNA repair in xeroderma pigmentosum group A cell extracts by a protein with affinity for damaged DNA. The EMBO Journal 10, 3913-3921.

RUPP, W. D. \& HowARD-Flanders, P. (1968). Discontinuities in the DNA synthesized in an excision-defective strain of Escherichia coli following ultraviolet irradiation. Journal of Molecular Biology 31, 291-304.

Saijo, M., Kuraoka, I., Masutani, C., Hanaoka, F. \& Tanaka, K. (1996). Sequential binding of DNA repair proteins RPA and ERCC1 to XPA in vitro. Nucleic Acids Research 24, 4719-4724.

SANCAR, A. \& TANG, M. S. (1993). Nucleotide excision repair. Photochemistry and Photobiology 57, 905-921.

Schaeffer, L., Roy, R., Humbert, S., Moncollin, V., Vermeulen, W., Hoeijmakers, J. H., Chambon, P. \& Egly, J. M. (1993). DNA repair helicase: a component of BTF2 (TFIIH) basic transcription factor. Science 260, 58-63.

SCHARER, O. D. (2013). Nucleotide excision repair in eukaryotes. Cold Spring Harbor Perspectives Biology 5, a012609.

SCHORR, S. \& CARELL, T. (2010a). Mechanism of acetylaminofluorene-dG induced frameshifting by polymerase eta. Chembiochem 11, $2534-2537$.

SChorr, S., Schneider, S., LAmmens, K., Hopfner, K. P. \& CArell, T. (2010b). Mechanism of replication blocking and bypass of Y-family polymerase $\eta$ by bulky acetylaminofluorene DNA adducts. Proceedings of the National Academy of Sciences of the United States of America 107, 20720-20725.

Schweizer, U., Hey, T., Lipps, G. \& Krauss, G. (1999). Photocrosslinking locates a binding site for the large subunit of human replication protein A to the damaged strand of cisplatin-modified DNA. Nucleic Acids Research 27, 3183-3189.

Scrima, A., Konickova, R., Czyzewski, B. K., Kawasaki, Y., Jeffrey, P. D., Groisman, R., Nakatani, Y., Iwai, S., Pavletich, N. P. \& Thoma, N. H. (2008). Structural basis of UV DNA-damage recognition by the DDB1-DDB2 complex. Cell 135, 1213-1223.

Shin, D. S., Pellegrini, L., Daniels, D. S., Yelent, B., Craig, L., Bates, D., Yu, D. S., Shivji, M. K., Hitomi, C., Arvai, A. S., Volkmann, N., Tsuruta, H., Blundell, T. L., Venkitaraman, A. R. \& Tainer, J. A. (2003). Full-length archaeal Rad51 structure and mutants: mechanisms for RAD51 assembly and control by BRCA2. The EMBO Journal 22, 4566-4576.

Shivj, M. K., Podust, V. N., Hubscher, U. \& Wood, R. D. (1995). Nucleotide excision repair DNA synthesis by DNA polymerase epsilon in the presence of PCNA, RFC, and RPA. Biochemistry 34, 5011-5017.

Sijbers, A. M., de laat, W. L., Ariza, R. R., Biggerstaff, M., Wei, Y. F., Moggs, J. G., Carter, K. C., Shell, B. K., Evans, E., De Jong, M. C., Rademakers, S., De Rooij, J., Jaspers, N. G., HoeijMakers, J. H. \& Wood, R. D. (1996). Xeroderma pigmentosum group F caused by a defect in a structure-specific DNA repair endonuclease. Cell 86, 811-822.

Silverstein, T. D., Jain, R., Johnson, R. E., Prakash, L., Prakash, S. \& Aggarwal, A. K. (2010a). Structural basis for error-free replication of oxidatively damaged DNA by yeast DNA polymerase eta. Structure 18, 1463-1470.

Silverstein, T. D., Johnson, R. E., Jain, R., Prakash, L., Prakash, S. \& Aggarwal, A. K. (2010b). Structural basis for the suppression of skin cancers by DNA polymerase eta. Nature 465, 1039-1043.

Singh, S., Folkers, G. E., Bonvin, A. M., Boelens, R., Wechselberger, R., Niztayev, A. \& Kaptein, R. (2002). Solution structure and DNA-binding properties of the C-terminal domain of UvrC from E.coli. The EMBO Journal 21, 6257-6266.

Staresincic, L., Fagbemi, A. F., Enzlin, J. H., Gourdin, A. M., Wijgers, N., Dunand-Sauthier, I., Giglia-Mari, G., Clarkson, S. G., Vermeulen, W. \& SCHARER, O. D. (2009). Coordination of dual incision and repair synthesis in human nucleotide excision repair. The EMBO Journal $\mathbf{2 8}$, $1111-1120$.

Story, R. M. \& Steitz, T. A. (1992). Structure of the recA protein-ADP complex. Nature 355, 374-376.

Sugasana, K., NG, J. M., Masutani, C., Inai, S., van der Spek, P. J., Eker, A. P., Hanaoka, F., Bootsma, D. \& Hoeijmakers, J. H. (1998). Xeroderma pigmentosum group C protein complex is the initiator of global genome nucleotide excision repair. Molecular Cell 2, 223-232.

Sugasawa, K., Okamoto, T., Shimizu, Y., Masutani, C., Inai, S. \& Hanaoka, F. (2001). A multistep damage recognition mechanism for global genomic nucleotide excision repair. Genes \& Development 15, 507-521.

Sugasama, K., Okuda, Y., Saijo, M., Nishi, R., Matsuda, N., Chu, G., Mori, T., Iwai, S., Tanaka, K., Tanaka, K., Hanaoka, F. (2005). UV-induced ubiquitylation of XPC protein mediated by UV-DDB-ubiquitin ligase complex. Cell 121, 387-400.

SugASAWA, K., Shimizu, Y., IwaI, S. \& HanaOKA, F. (2002). A molecular mechanism for DNA damage recognition by the xeroderma pigmentosum group C protein complex. DNA Repair 1, 95-107. 
Sugitani, N., Shell, S. M., Soss, S. E. \& Chazin, W. J. (2014). Redefining the DNA-binding domain of human XPA. Journal of the American Chemical Society 136, 10830-10833.

Sung, P., Higgins, D., Prakash, L. \& Prakash, S. (1988). Mutation of lysine-48 to arginine in the yeast RAD3 protein abolishes its ATPase and DNA helicase activities but not the ability to bind ATP. The EMBO Journal 7, 3263-3269.

Sweder, K. S. \& Hanawalt, P. C. (1992). Preferential repair of cyclobutane pyrimidine dimers in the transcribed strand of a gene in yeast chromosomes and plasmids is dependent on transcription. Proceedings of the National Academy of Sciences of the United States of America 89, 10696-10700.

Takao, M., Abramic, M., Moos, M. Jr., Otrin, V. R., Wootton, J. C., McLenigan, M., Levine, A. S. \& Protic, M. (1993). A 127 kDa component of a UV-damaged DNA-binding complex, which is defective in some xeroderma pigmentosum group E patients, is homologous to a slime mold protein. Nucleic Acids Research 21, 4111-4118.

Tang, J. Y., Hwang, B. J., Ford, J. M., Hanawalt, P. C. \& Chu, G. (2000). Xeroderma pigmentosum p48 gene enhances global genomic repair and suppresses UV-induced mutagenesis. Molecular Cell 5, 737-744.

TANTIN, D. (1998). RNA polymerase II elongation complexes containing the Cockayne syndrome group B protein interact with a molecular complex containing the transcription factor IIH components xeroderma pigmentosum B and p62. The Journal of Biological Chemistry 273, 27794-27799.

TANTin, D., Kansal, A. \& CAREY, M. (1997). Recruitment of the putative transcription-repair coupling factor CSB/ERCC6 to RNA polymerase II elongation complexes. Molecular and Cellular Biology 17, 6803-6814.

Tapias, A., Auriol, J., Forget, D., Enzlin, J. H., Scharer, O. D., Coin, F., Coulombe, B. \& Egly, J. M. (2004). Ordered conformational changes in damaged DNA induced by nucleotide excision repair factors. The Journal of Biological Chemistry 279, 19074-19083.

Thoma, B. S. \& VAsquez, K. M. (2003). Critical DNA damage recognition functions of XPC-hHR23B and XPA-RPA in nucleotide excision repair. Molecular Carcinogenesis 38, 1-13.

Thorel, F., Constantinou, A., Dunand-Sauthier, I., Nouspikel, T., Lalle, P., Raams, A., Jaspers, N. G., Vermeulen, W., Shivji, M. K., Wood, R. D. \& Clarkson, S. G. (2004). Definition of a short region of XPG necessary for TFIIH interaction and stable recruitment to sites of UV damage. Molecular and Cellular Biology 24, 10670-10680.

Tirode, F., Busso, D., Coin, F. \& Egly, J. M. (1999). Reconstitution of the transcription factor TFIIH: assignment of functions for the three enzymatic subunits, XPB, XPD, and cdk7. Molecular Cell 3, 87-95.

Tornaletti, S. \& Hanawalt, P. C. (1999). Effect of DNA lesions on transcription elongation. Biochimie 81, 139-146.

Trincao, J., Johnson, R. E., Escalante, C. R., Prakash, S., Prakash, L. \& Aggarwal, A. K. (2001). Structure of the catalytic core of S. cerevisiae DNA polymerase eta: implications for translesion DNA synthesis. Molecular Cell 8, 417-426.

Tripsianes, K., Folkers, G., AB, E., Das, D., Odijk, H., Jaspers, N. G., Hoeijmakers, J. H., Kaptein, R. \& Boelens, R. (2005). The structure of the human ERCC1/XPF interaction domains reveals a complementary role for the two proteins in nucleotide excision repair. Structure 13, $1849-1858$.

Tripsianes, K., Folkers, G. E., Zheng, C., Das, D., Grinstead, J. S., Kaptein, R. \& Boelens, R. (2007). Analysis of the XPA and ssDNA-binding surfaces on the central domain of human ERCC1 reveals evidence for subfunctionalization. Nucleic Acids Research 35, 5789-5798.

Tsodikov, O. V., Enzlin, J. H., Scharer, O. D. \& Ellenberger, T. (2005). Crystal structure and DNA binding functions of ERCC1, a subunit of the DNA structure-specific endonuclease XPF-ERCC1. Proceedings of the National Academy of Sciences of the United States of America 102, 11236-11241.

Tsodikov, O. V., Ivanov, D., Orelli, B., Staresincic, L., Shoshani, I., Oberman, R., Scharer, O. D., Wagner, G. \& Ellenberger, T. (2007). Structural basis for the recruitment of ERCC1-XPF to nucleotide excision repair complexes by XPA. The EMBO Journal 26, $4768-4776$.

Tsutakawa, S. E., Classen, S., Chapados, B. R., Arvai, A. S., Finger, L. D., Guenther, G., Tomlinson, C. G., Thompson, P., Sarker, A. H., Shen, B., Cooper, P. K., Grasby, J. A. \& Tainer, J. A. (2011). Human flap endonuclease structures, DNA double-base flipping, and a unified understanding of the FEN1 superfamily. Cell 145, 198-211.

Tuteja, N. \& Tuteja, R. (1996). DNA helicases: the long unwinding road. Nature Genetics 13, 11-12.

Van der Spek, P. J., Eker, A., Rademakers, S., Visser, C., Sugasawa, K., Masutani, C., Hanaoka, F., Bootsma, D. \& Hoeijmakers, J. H. (1996). XPC and human homologs of RAD23: intracellular localization and relationship to other nucleotide excision repair complexes. Nucleic Acids Research 24, 2551-2559.

Venema, J., van Hoffen, A., Karcagi, V., Natarajan, A. T., van Zeeland, A. A. \& Mullenders, L. H. (1991). Xeroderma pigmentosum complementation group C cells remove pyrimidine dimers selectively from the transcribed strand of active genes. Molecular and Cellular Biology 11, 4128-4134.

Volker, M., Mone, M. J., Karmakar, P., van Hoffen, A., Schul, W., Vermeulen, W., Hoeijmakers, J. H., van Driel, R., van Zeeland, A. A. \& Mullenders, L. H. (2001). Sequential assembly of the nucleotide excision repair factors in vivo. Molecular Cell 8, 213-224.

Wakasugi, M., Kawashima, A., Morioka, H., Linn, S., Sancar, A., Mori, T., Nikaido, O. \& Matsunaga, T. (2002). DDB accumulates at DNA damage sites immediately after UV irradiation and directly stimulates nucleotide excision repair. The Journal of Biological Chemistry 277, $1637-1640$.

WAKASUGI, M. \& SANCAR, A. (1998). Assembly, subunit composition, and footprint of human DNA repair excision nuclease. Proceedings of the National Academy of Sciences of the United States of America 95, 6669-6674.

WaKasugi, M. \& SANCAR, A. (1999). Order of assembly of human DNA repair excision nuclease. The Journal of Biological Chemistry 274, 18759-18768.

Wang, M., Mahrenholz, A. \& Lee, S. H. (2000). RPA stabilizes the XPA-damaged DNA complex through protein-protein interaction. Biochemistry 39, 6433-6439. 
Wang, H., Zha, L., Xu, J., Joo, H. Y., Jackson, S., Erdjument-Bromage, H., Tempst, P., Xiong, Y. \& Zhang, Y. (2006). Histone H3 and H4 ubiquitylation by the CUL4-DDB-ROC1 ubiquitin ligase facilitates cellular response to DNA damage. Mol. Cell 22, 383-394.

Weir, H. M., Kraulis, P. J., Hill, C. S., Raine, A. R., Laue, E. D. \& Thomas, J. O. (1993). Structure of the HMG box motif in the B-domain of HMG1. The EMBO Journal 12, 1311-1319.

Whiтe, M. F. (2009). Structure, function and evolution of the XPD family of iron-sulfur-containing $5^{\prime} \rightarrow>3^{\prime}$ DNA helicases. Biochemical Society Transactions 37, 547-551.

Winkler, G. S., Araujo, S. J., Fiedler, U., Vermeulen, W., Coin, F., Egly, J. M., Hoeijmakers, J. H., Wood, R. D., Timmers, H. T. \& Weeda, G. (2000). TFIIH with inactive XPD helicase functions in transcription initiation but is defective in DNA repair. The Journal of Biological Chemistry 275, 4258-4266.

Wolski, S. C., Kuper, J., Hanzelmann, P., Truglio, J. J., Croteau, D. L., Van Houten, B. \& Kisker, C. (2008). Crystal structure of the FeS clustercontaining nucleotide excision repair helicase XPD. PLoS Biology 6, e149.

Wood, R. D. (1997). Nucleotide excision repair in mammalian cells. The Journal of Biological Chemistry 272, 23465-23468.

Yan, H., Yuan, W., Velculescu, V. E., Vogelstein, B. \& Kinzler, K. W. (2002). Allelic variation in human gene expression. Science $297,1143$.

Yan, S., Wu, M., Buterin, T., Naegeli, H., Geacintov, N. E. \& Broyde, S. (2003). Role of base sequence context in conformational equilibria and nucleotide excision repair of benzo[a]pyrene diol epoxide-adenine adducts†े. Biochemistry 42, 2339-2354.

Yang, Z., Roginskaya, M., Colis, L. C., Basu, A. K., Shell, S. M., Liu, Y., Musich, P. R., Harris, C. M., Harris, T. M. \& Zou, Y. (2006). Specific and efficient binding of xeroderma pigmentosum complementation group A to double-strand/single-strand DNA junctions with $3^{\prime}$ - and/or 5'-ssDNA branches. Biochemistry 45, 15921-15930.

Yang, Z. G., LiU, Y., MaO, L. Y., Zhang, J. T. \& Zou, Y. (2002). Dimerization of human XPA and formation of XPA2-RPA protein complex. Biochemistry 41, 13012-13020.

Yasui, M., Dong, H., Bonala, R. R., Suzuki, N., Ohmori, H., Hanaoka, F., Johnson, F., Grollman, A. P. \& Shibutani, S. (2004). Mutagenic properties of 3-(deoxyguanosin-N2-yl)-2-acetylaminofluorene, a persistent acetylaminofluorene-derived DNA adduct in mammalian cells. Biochemistry 43, 15005-15013.

Yeh, J. I., Levine, A. S., Du, S., Chinte, U., Ghodke, H., Wang, H., Shi, H., Hsieh, C. L., Conway, J. F., Van Houten, B. \& Rapić-Otrin, V. (2012). Damaged DNA induced UV-damaged DNA-binding protein (UV-DDB) dimerization and its roles in chromatinized DNA repair. Proceedings of the National Academy of Sciences of the United States of America 109, E2737-E2746. 